\title{
Research Square \\ Research on the Effects of Yttrium on Bismuth Titanate Borosilicate Glass System
}

Kh. S. shaaban ( $\nabla$ khamies1078@yahoo.com )

Al-Azhar University https://orcid.org/0000-0002-5969-3089

\section{Research Article}

Keywords: Glasses, Y203, elastic modulus, radiation shielding

Posted Date: March 15th, 2021

DOI: https://doi.org/10.21203/rs.3.rs-283869/v1

License: (c) (i) This work is licensed under a Creative Commons Attribution 4.0 International License. Read Full License

Version of Record: A version of this preprint was published at Silicon on April 25th, 2021. See the published version at https://doi.org/10.1007/s12633-021-01125-0. 


\title{
Research on the effects of yttrium on bismuth titanate borosilicate glass system
}

Kh. S. Shaaban ${ }^{1, *}$

${ }^{1}$ Chemistry Department, Faculty of Science, Al-Azhar University, P.O. 71524, Assiut, Egypt.

\begin{abstract}
Glasses with the chemical composition of $52 \mathrm{~B}_{2} \mathrm{O}_{3}-12 \mathrm{SiO}_{2}-26 \mathrm{Bi}_{2} \mathrm{O}_{3}-(10-x) \mathrm{TiO}_{2}$ $-x \mathrm{Y}_{2} \mathrm{O}_{3},:(0 \leq x \geq 10)$ prepared using the melt-quench method. The goal of this study is to investigate the structural, mechanical, and radiation shielding characteristics of these samples. XRD analysis has explored the nature of the glass system. Molar volume obtained reduced while the density denotes increased in the present system. As the molar volume decrease interionic distance, polaron radius, inter-nuclear distance, and Y-Y separation of the investigated glasses decreased. The mechanical characteristics depend on the glass structure of the current glasses sample. Ultrasonic velocities and elastic moduli (experimental and theoretical) for these glasses obtained observed to get enhanced. The radiation shielding efficiency investigated by Phy-X/PSD software. The mass attenuation coefficient $(\mu / \rho)$ mean free path (MFP), half-value layer (HVL), tenth value layer (TVL), and effective atomic number (Zeff), of glasses, have designed to simulate for gamma photon energies between 0.015 and $15 \mathrm{MeV}$.
\end{abstract}

Keywords: Glasses; $\mathrm{Y}_{2} \mathrm{O}_{3}$; elastic modulus; radiation shielding

*Corresponding Authors: Emails: khamies1078@yahoo.com, 


\section{Introduction}

Due to the importance of glass materials containing many transition metal ions (TMI) for many applications, these glasses have existed intersected over the past few years. In specific, the glass based on $\mathrm{B}_{2} \mathrm{O}_{3}$ and $\mathrm{SiO}_{2}$ has become common among a wide variety of glass systems, keeping in mind its glass status, transparency, and a variety of physical and chemical properties. The B element can transform its coordination number between 3 and 4 with oxygen supplying by modification of metal cations [1-5]. Due to their unique properties such as hardness, transparency, UV-transmission ability, and corrosion resistance, $\mathrm{SiO}_{2}-\mathrm{B}_{2} \mathrm{O}_{3}$ glasses investigated for many years. $\mathrm{B}_{2} \mathrm{O}_{3}-\mathrm{SiO}_{2}$ glass modified with $\mathrm{Bi}_{2} \mathrm{O}_{3}$ characterized by its excellent optical, mechanical, radiation, and electrical properties [5-12].

The physical characteristics of the glass change based on its formulation and can linked with the network structures and interatomic forces. Glasses with more bridging oxygen (BOs) have a more compact glass framework and high elastic moduli. Introducing $\mathrm{Y}_{2} \mathrm{O}_{3}$ to $\mathrm{SiO}_{2}$ $\mathrm{B}_{2} \mathrm{O}_{3}$ glasses provide chemical stability durability, a vast compositional variety of glass forming, and increased transmission with promising properties reported. The presence of trivalent oxide like $\mathrm{Y}_{2} \mathrm{O}_{3}$ in borosilicate glass exhibits dual nature as former or intermediate in the glass network. These glasses obtained noticed to withstand atmospheric moisture and are accept a good quantity of doping transition metal (TM) or rare-earth (REs) [13-14].

Glasses doped intermediate oxides such as $\mathrm{TiO}_{2}$ and $\mathrm{Y}_{2} \mathrm{O}_{3}$ have specific mechanical and optical characteristics such as hardness, elastic moduli, and higher refractive index [1518]. It is also significant to observe that the inclusion of $\mathrm{Y}_{2} \mathrm{O}_{3}$ improves the capability of $\mathrm{UV}$ transmission, enhances thermal stability and chemical durability. The emergence of $\mathrm{Y}_{2} \mathrm{O}_{3}$ into the glass network improved the glass's mechanical, thermal, and shielding characteristics [19]. Because of the good conductivity of these glasses in ionic terms, it is probable to use them in UV optics, solid-state batteries, and radiation protection. These glasses possess lower photon 
energy and a greater refractive index than other glasses. The significant development of bismuth yttrium titanate borosilicate glasses is very important scientifically and technologically.

The creativity of this research paper reflected in the structural, mechanical, and radiation shielding characteristics of $\mathrm{B}_{2} \mathrm{O}_{3}-\mathrm{SiO}_{2}-\mathrm{Bi}_{2} \mathrm{O}_{3}-\mathrm{TiO}_{2}$ glass undoped and doped with $\mathrm{Y}^{+3}$ ions.

\section{Methodology}

Five glass samples in Table 1 with the nominal compositions $52 \mathrm{~B}_{2} \mathrm{O}_{3}-12 \mathrm{SiO}_{2}-$ $26 \mathrm{Bi}_{2} \mathrm{O} 3-\mathrm{TiO}_{2}-\mathrm{Y}_{2} \mathrm{O}_{3}$, prepared using the solid-state conventional method. By melting together specific weights of $\mathrm{B}_{2} \mathrm{O}_{3}$ in the form of $\mathrm{H}_{3} \mathrm{BO}_{4}$ (Merck), $\mathrm{SiO}_{2}$ (Aldrich), $\mathrm{Bi}_{2} \mathrm{O}_{3}$ (Merck), $\mathrm{TiO}_{2}$ (Merck), and $\mathrm{Y}_{2} \mathrm{O}_{3}$ (Merck) in an open porcelain crucible. $\mathrm{H}_{3} \mathrm{BO}_{4}$ converted into $\mathrm{B}_{2} \mathrm{O}_{3}$ after the $\mathrm{H} 2 \mathrm{O}$ evaporation process throughout the melting in porcelain crucibles. Thus, it is possible to estimate the required amount of oxide to match the chemical formula used by knowing the molecular weight of $\mathrm{H}_{3} \mathrm{BO}_{4}$, and $\mathrm{B}_{2} \mathrm{O}_{3}$. The porcelain crucible with the blend kept at $650{ }^{\circ} \mathrm{C}$ for 45 minutes to decrease the tendency to volatilize. The furnace temperature programmed to rise to the melting temperature at $1150{ }^{\circ} \mathrm{C}$ and kept for 50 minutes. The melting glass was cast in a clean stainless-steel mold. After that, glass samples annealed at $400{ }^{\circ} \mathrm{C}$ to remove the internal stresses.

To verify the status of fabricated glasses, the Philips X-ray diffractometer (model PW/1710) used. The densities of glasses quantified by the Archimedes method. $\rho=\rho_{0}\left(\frac{M}{M-M_{1}}\right)$ where $M$ and $M_{1}$ are the weights of samples in air and fluid, the glass density is $\rho$ and the density of toluene is $\rho_{0}\left(0.865 \mathrm{~g} . \mathrm{cm}^{-3}\right)$ with error $\pm 0.001 \mathrm{~g} . \mathrm{cm}^{-3}$. Using a pulse-echo method, the ultrasonic velocities estimation characterized (Echograph model 1085). The molar volume

can evaluate as $V_{m}=\frac{M}{\rho}$ where $\mathrm{M}$ the molar weight of the glass. Besides the density, the velocities used to evaluate elastic moduli. longitudinal waves $L=\rho v_{l}^{2}$, transverse waves $G=$ 
$\rho v_{t}^{2}$, Young's modulus $Y=(1+\sigma) 2 G$, bulk modulus $K=L-\left(\frac{4}{3}\right) G$ The elastic moduli of the samples can be evaluated using the exemplary [31,32] based on packing density $V i=$ $\left(\frac{3 \pi}{4}\right) N_{A}\left(m \mathrm{R}_{\mathrm{A}}^{3}+n \mathrm{R}_{\mathrm{O}}^{3}\right) m^{3} \cdot m o l^{-1}$, and dissociation energy $G i=\left(\frac{1}{V_{m}}\right) \sum_{i} G i X i$, the metallic and oxygen Pauling ionic radii are $R_{m}$ and $R_{O}$. Longitudinal waves

$$
L=K+\left(\frac{4}{3}\right) G
$$
transverse waves $G=30 *\left(\frac{V_{i}^{2} G_{i}}{V_{i}}\right)$ Young's modulus $Y=8.36 V_{i} G_{i}$, bulk modulus $K=$ $10 V_{i}^{2} G_{i}$. Poisson's ratio $\quad \sigma=\frac{1}{2}-\left(\frac{1}{7.2^{*} V i}\right)$. Acoustic Impedance; $Z=v_{L} \rho$. Micro Hardness; $\quad \mathrm{H}=\frac{(1-2 \sigma) \mathrm{Y}}{6(1+\sigma)}$. Debye Temperature: $\theta_{D}=\frac{h}{k}\left(\frac{9 N_{A}}{4 \pi V_{m}}\right)^{\frac{1}{3}} M_{S}$, Where $h$ and $k$ are the constants of Planck and Boltzmann and $N_{A}$ is the number of Avogadro [20-21].

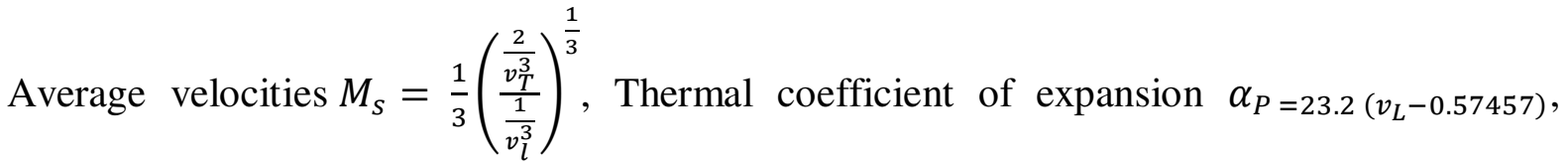
the oxygen molar volume $V_{O}=\left(\frac{M}{\rho}\right)\left(\frac{1}{\Sigma x i n i}\right)$, Oxygen Packing Density $O P D=\left(\frac{1000 C}{V m}\right)\left(\frac{M o l}{L}\right)$.

In this article, radiation parameters have computed using Phy-X/PSD software [19] and these parameters calculated using the following equations: Beer-Lambert law $\mu=-\frac{\ln \frac{I}{I_{o}}}{x}$, Where $\mu$ the linear attenuation coefficient $\left(\mathrm{cm}^{-1}\right) \mathrm{I}_{0}$ and I respectively, the coefficient of mass attenuation samples $(\mu / \rho)=\sum_{i} x_{i}(\mu / \rho)_{i}$. Effective atomic number $Z_{e f f}=\frac{\sum_{i} f_{i} A_{i}(\mu / \rho)_{i}}{\sum_{j} f_{j} \frac{A_{j}}{Z_{j}}(\mu / \rho)_{j}}$. Half and tenth value layer (HVL), and (TVL): $H V L=\frac{0.693}{L A C}, T V L=\frac{2.3}{L A C}$. The mean free path (MFP) was predictable as $M E P=\left(\frac{1}{\mu}\right)$.

\section{Results and Discussions}

\subsection{XRD}

The XRD characteristic of $\mathrm{B}_{2} \mathrm{O}_{3}-\mathrm{Bi}_{2} \mathrm{O}_{3}-\mathrm{SiO}_{2}-\mathrm{TiO}_{2}-\mathrm{Y}_{2} \mathrm{O}_{3}$ glass with a wide hollow band at $2 \theta^{\circ}$ between $\left(20^{\circ}-30^{\circ}\right)$ demonstrated in Fig. 1, which signifies the amorphous status of 
the glass. The width of the small mound differs from one sample to another but is not no indications of the crystalline phases have displayed in all the glasses.

\subsection{Structural Studies}

Different factors, such as chemical constituents and internal structure have affected the density of $52 \mathrm{~B}_{2} \mathrm{O}_{3}-12 \mathrm{SiO}_{2}-26 \mathrm{Bi}_{2} \mathrm{O}_{3}-(10-x) \mathrm{TiO}_{2}-x \mathrm{Y}_{2} \mathrm{O}_{3}$, where $x:(0 \leq x \geq 10)$ glass system. Its values are in the range $4.213-5.07 \mathrm{~g} / \mathrm{cm}^{3}$ for different glass compositions and follow a linear trend. The density of the glass under investigation increases with the increment in the content of $\mathrm{Y}_{2} \mathrm{O}_{3}$. This observation because of the high $\mathrm{Y}_{2} \mathrm{O}_{3}$ density $\left(5.03 \mathrm{~g} / \mathrm{cm}^{3}\right)$ relative to $\mathrm{TiO}_{2}\left(4.23 \mathrm{~g} / \mathrm{cm}^{3}\right)$ and the high $\mathrm{Y}_{2} \mathrm{O}_{3}$ atomic mass (225.81) relative to $\mathrm{TiO}_{2}$ (79.866). The emergence of $\mathrm{Y}_{2} \mathrm{O}_{3}$ in a glass matrix enhances the structural network by raising the oxygen level, resulting in the transformation of $\mathrm{BO}_{3}$ into $\mathrm{BO}_{4}$ units, and may also another reason lead to an increase in glass density. In the science of glass, the molar volume also plays an important role. The reduction in molar volume could related to the formation of bridging oxygens that reduce the voids within the configuration. The density and molar volume of $\mathrm{B}_{2} \mathrm{O}_{3}-\mathrm{Bi}_{2} \mathrm{O}_{3}-\mathrm{SiO}_{2}-$ $\mathrm{TiO}_{2}-\mathrm{Y}_{2} \mathrm{O}_{3}$ glasses exemplified in Fig. 2.

OPD value of $\mathrm{B}_{2} \mathrm{O}_{3}-\mathrm{Bi}_{2} \mathrm{O}_{3}-\mathrm{SiO}_{2}-\mathrm{Y}_{2} \mathrm{O}_{3}$ sample is higher in comparison with that of $\mathrm{B}_{2} \mathrm{O}_{3}-\mathrm{Bi}_{2} \mathrm{O}_{3}-\mathrm{SiO}_{2}-\mathrm{TiO}_{2}$ sample. As a result of the creation of new links among $\mathrm{YO}_{6}$ and the other structural units established in the glass matrices, this can accredit to the increasing network connectivity. Due to the formation of new linked B-O-Y bonds, the significant increase in OPD, which is an indicator of the packing stiffness of the oxide network, suggests a packed amorphous structure. The increase in OPD with the addition of $\mathrm{Y}_{2} \mathrm{O}_{3}$ is also accredited to the creation of bridging oxygen $(\mathrm{BO})$.

$\mathrm{V}_{\mathrm{o}}$ value of $\mathrm{B}_{2} \mathrm{O}_{3}-\mathrm{Bi}_{2} \mathrm{O}_{3}-\mathrm{SiO}_{2}-\mathrm{Y}_{2} \mathrm{O}_{3}$ sample is lower in comparison with that of $\mathrm{B}_{2} \mathrm{O}_{3}$ $\mathrm{Bi}_{2} \mathrm{O}_{3}-\mathrm{SiO}_{2}-\mathrm{TiO}_{2}$ sample. $\mathrm{V}_{\mathrm{o}}$ shows an inverse sequence with OPD. The reduction in $\mathrm{V}_{\mathrm{o}}$ with the addition of $\mathrm{Y}_{2} \mathrm{O}_{3}$ may accredited to the decrease in the $\mathrm{V}_{\mathrm{m}}$. The decreasing trend in $\mathrm{V}_{\mathrm{o}}$ can 
related to NBO disappearing and $\mathrm{BO}$ creation. OPD and $\mathrm{V}_{\mathrm{m}}$ of $\mathrm{B}_{2} \mathrm{O}_{3}-\mathrm{Bi}_{2} \mathrm{O}_{3}-\mathrm{SiO}_{2}-\mathrm{TiO}_{2}-\mathrm{Y}_{2} \mathrm{O}_{3}$ glasses exemplified in Fig. 3.

$\mathrm{Y}^{+3}$ concentration computed $Y^{+3}=\left(\frac{6.023 \times 10^{23} \times \text { mol fraction of cation } \times \text { valency of cation }}{V m}\right)$.

Because of molar volume reduction, it exemplified $\left(\mathrm{Y}^{+3}\right)$ enhanced. Quantified inter-ionic distance, $R_{i}=\left(\frac{1}{\text { Concentration of } \mathrm{Y}}\right)^{\frac{1}{3}}$, the radius determined as polaron $\mathrm{r}_{\mathrm{p}}$ and internuclear $\mathrm{r}_{\mathrm{i}}$, including both, $r p=\frac{1}{2}\left(\frac{\pi}{6 N}\right)^{\frac{1}{3}}, r i=\left(\frac{1}{N}\right)^{\frac{1}{3}}$. $\mathrm{Y}-\mathrm{Y}$ separation $\left(\mathrm{d}_{\mathrm{Y}^{-} \mathrm{Y}}\right)$ computed as $(\mathrm{dY}-\mathrm{Y})=$ $\left(\frac{V_{m}^{B}}{N}\right)^{\frac{1}{3}}$ and $V_{m}^{B}=\frac{V m}{2(1-2 \mathrm{Xn})}$. It has confirmed that these perceived values reduce with $\mathrm{Y}$, because of the reduction in molar volume. With the addition of $\mathrm{Y}_{2} \mathrm{O}_{3}$ content, these parameters decrease, which indicates that the network is more compact because of the creation (BO). This information described in Table 2.

For $\mathrm{BO}$ or $\mathrm{NBO}$ connection confirmation, the coordinated average number is a significant criterion and characterized as $m=\sum n_{c i} X_{i}$ where cation coordination is $n_{c i}$. It noticed that $\mathrm{m}$ increases with an increase in $\mathrm{Y}_{2} \mathrm{O}_{3}$ content. Calculate the number of bonds per unit as $n_{b}=\frac{N_{A}}{V_{m}} \sum n_{c i} X_{i}$. It discovered that perceived $n_{b}$ through $\mathrm{Y}_{2} \mathrm{O}_{3}$ content increased.

The glass network influenced by the total number of mechanical constraints and computed as $N_{c o n}=N_{b s}+N_{b b}$ where $N_{b b}$ is bond bending constraints and $N_{b s}$ is bond stretching, $N_{b b}=\frac{\sum x i m}{2}, N_{b s}=\sum x i(2 m-3)$. The $N_{c o n}, N_{b s}$ and $N_{b b}$. It observed that, with an increment in $\mathrm{Y}_{2} \mathrm{O}_{3}$, the overall constraints of $N_{\text {con }}$ are expected to enhance. Floppy modes considered as $M_{f}=2-\frac{5 m}{6}$, cross-linking density $\mathrm{D}_{\mathrm{CL}}$ considered as $D_{c l}=N_{c o n}-2$, $C N_{\text {eff }}=\frac{2}{5} N_{\text {con }}+3$. Results calculated to increase with increasing $\mathrm{Y}_{2} \mathrm{O}_{3}$ content. From the data result, it can thus, suggested that the glass 's retained its $2 \mathrm{D}$ network with an increment in $\mathrm{Y}_{2} \mathrm{O}_{3}$. 


\subsection{Ultrasonic studies}

Figure 4 exemplified the ultrasonic velocities $\left(v_{L \&} v_{T}\right)$ of the glass samples with $\mathrm{Y}_{2} \mathrm{O}_{3}$ content [33-34]. As exemplified in Fig. 4, the ultrasonic velocity of these samples enhanced by an increment in the $\mathrm{Y}_{2} \mathrm{O}_{3}$ concentration. Particularly, the increment in ultrasonic velocities was due to an increment in the network structure's connectivity. Thus, the transformation of the essential glass former $\mathrm{B}_{2} \mathrm{O}_{3}$ from $\mathrm{BO}_{3}$ units to $\mathrm{BO}_{4}$ units with increasing $\mathrm{Y}_{2} \mathrm{O}_{3}$ concentration explained the increase in both ultrasonic wave velocities in the investigated glass system. The structural groups of $\mathrm{BO}_{4}$ are denser than $\mathrm{BO}_{3}$ and are accountable for increment the binding of the glass structure and the compactness [22-23].

In this article, the elastic moduli behave in the manner as observed for ultrasonic velocities as shown in Figs. 5\&6. With the addition of $\mathrm{Y}_{2} \mathrm{O}_{3}$ content, the values of elastic moduli demonstrated a significant increase. The increment in elastic modules with an increment in $\mathrm{Y}_{2} \mathrm{O}_{3}$ concentration was due to an increase in the number of coordinates and higher bond strength of $\mathrm{YO}_{6}$ relative to $\mathrm{BO}_{3}$ structural units.

A glass matrix's dimensionality $(d)$ can attribute to the elastic moduli as $d=4 *\left(\frac{G}{K}\right)$. For the examined glasses, the $\mathrm{d}$ values are about 2.2, i.e., the structure is a three-dimensional one with more cross-links that are increasing. The Poisson ratio of these glasses demonstrated a constant value of about $0.27 \pm 002$. This value may have attributed to slight changes in the glass structure cross-link density. In identifying elastic moduli and atomic vibrations, the Debye temperature $\left(\theta_{D}\right)$ plays an important role. It considered that $\theta_{D}$ relies immediately on upon $M_{s}$. Thus, as $\mathrm{Y}_{2} \mathrm{O}_{3}$ content increases, $\theta_{D}$ and $M_{s}$ increases as Fig. 7. This enhanced because of the conversion of $\mathrm{BO}_{3}$ to $\mathrm{YO}_{6}$, the expansion in cross-link density, and the structure of the glass connectivity. The values of $V_{i}, G_{i}, H, Z$, and $\alpha$ increased by the addition of $\mathrm{Y}_{2} \mathrm{O}_{3}$ as explained before. This information described in Figs. 8,9\&10.

\subsection{Photon shielding studies}


By using Phy-X/PSD source code, the photon shielding competencies for the investigated glass under study have introduced. For the glass system, critical features, such as MAC, LAC, MFP, TVL, and HVL, quantified. The changes in MAC values with an energy range of $0.015-15 \mathrm{MeV}$ shown in Fig. 11. The highest values of MAC found at low energy, and with the shift towards greater energy, MAC decreased. The conduct of these concepts could attribute to the Photoelectric effect, Compton scattering, and pair production. On the other hand, due to the higher MAC value, we know that excellent photon shielding features can achieved. Comparable improvement in $\mathrm{MAC}$ values with $\mathrm{Y}_{2} \mathrm{O}_{3}$ increased. In comparison to various glass samples, Table 3 shows coefficients of mass attenuation (in $\mathrm{cm}^{2} / \mathrm{g}$ ) [24-30].

The average distance travelled by a movable photon collision identified by MFP, so evaluating the MFP is critical. Fig. 12 exemplified the MFP of the glass system against energy. It is obvious that with the increased photon energy, the MFP values are increasing. The MFP is ascending after certain photon energy, i.e., $0.1 \mathrm{meV}$. We can conclude that $\mathrm{Y}_{2} \mathrm{O}_{3}$ can establish MFP. Fig. 13 exemplified the MFP of the glass system compared with other glasses.

Photon shielding materials are generally linked to create an more comprehension HVL. Fig. 14 exemplified the HVL of the glass system against energy. It is obvious that with the increased photon energy, the HVL values are increasing. Fig. 15 exemplified the HVL of the glass system compared with other glasses. It becomes more competitive with heavyweight concrete due to the decreasing HVL value in the RS-253 sample. We can surmise that the investigated glasses have a greater potential to contribute to use these glasses as radiation shielding materials. Fig. 16 exemplified TVL of the glass system against energy. It is obvious that with the increased photon energy, the TVL values are increasing like HVL.

To determine the photon interactions of the glass system, $\mathrm{Z}_{\mathrm{eff}}$ and $\mathrm{N}_{\mathrm{eff}}$ values calculated in this article. The findings of the $\mathrm{Z}_{\mathrm{eff}}$ estimation linked to the radiation shielding function. Figs. $15 \& 16$ exemplified $Z_{\text {eff }}$ and $N_{\text {eff }}$ of glass system against energy. As is visible in Figs. $17 \& 18$ 
glass with a higher $\mathrm{Y}_{2} \mathrm{O}_{3}$ value usually has higher $\mathrm{Z}_{\text {eff }} \& \mathrm{~N}_{\text {eff }}$ values. $\mathrm{Z}_{\text {eff }} \& \mathrm{~N}_{\text {eff }}$ values decrease in the energy range $(0.01<$ energy $<1)$. In this selected region of energy, it can mention that Compton scattering is dominant. The highest $\mathrm{Z}_{\mathrm{eff}} \& \mathrm{~N}_{\text {eff }}$ values at the low-energy region and these alterations are insignificant. $Z_{\text {eff }} \& \mathrm{~N}_{\text {eff }}$ values reached to smallest value at the energy range $(1<$ energy < 5). As is visible in Figs. $17 \& 18$ Compton effects, pair production, and photoelectric effects, where $\mathrm{Z}_{\mathrm{eff}} \& \mathrm{~N}_{\text {eff }}$ values are dominant.

Fast neutron removal cross-section (FNRCS) shown in Fig. 19. It noted that FNRCS increased with $\mathrm{Y}_{2} \mathrm{O}_{3}$. We can say that the addition of $\mathrm{Y}_{2} \mathrm{O}_{3}$ to glass samples enhances the FNRCS. Fig. 19 exemplified FNRCS of glass system compared with other glasses as RS-253G18, RS-360, RS-520, chromite, and ferrite. It becomes more competitive with RS-253-G18, RS-360, RS-520, due to the increasing FNRCS value in the RS-253-G18, RS-360, and RS-520, samples. But it decreases the FNRCS value in the chromite and ferrite.

\section{Conclusions}

In the current study, five glass samples with the nominal compositions $52 \mathrm{~B}_{2} \mathrm{O}_{3}-12 \mathrm{SiO}_{2}$ $-26 \mathrm{Bi}_{2} \mathrm{O}_{3}-\mathrm{TiO}_{2}-\mathrm{Y}_{2} \mathrm{O}_{3}$, prepared using the solid-state conventional method. The structural, mechanical, and shielding variables examined for these glasses. XRD measurements established the amorphous nature of glasses. The density of these samples increased while molar volume decreased. In this article, the elastic moduli behave in the manner as observed for ultrasonic velocities. The ultrasonic velocity of these samples enhanced by an increment in the $\mathrm{Y}_{2} \mathrm{O}_{3}$ concentration. With the addition of $\mathrm{Y}_{2} \mathrm{O}_{3}$ content, the values of elastic moduli demonstrate a significant increase due to an increase in the number of coordination and high bond strength of $\mathrm{YO}_{6}$ relative to $\mathrm{BO}_{3}$ structural units. Gamma shielding characteristics of these glasses were predictable by the Phy-X / PSD program between $0.015-15 \mathrm{MeV}$. The effect of the addition of $\mathrm{Y}_{2} \mathrm{O}_{3}$ on the shielding ability of the glasses discussed and we found that: The mass attenuation coefficient increased with the increase of the concentration of $\mathrm{Y}_{2} \mathrm{O}_{3}$ from 0 
mol. \% to 10 mol. \%. The sample coded as G 5 possesses the lowest HVL while the highest Zeff. The results obtained have shown that the increase in $\mathrm{Y}_{2} \mathrm{O}_{3}$ concentration in the glass system can lead to a significant improvement in the attenuation and structural properties. Furthermore, it is possible to use present glass as a shield from radiation in the x-ray centres.

Author contributions: Kh. S. Shaaban: performing, XRD, mechanical measurements and analysis, Writing-review, writing the manuscript, Methodology, Software, and writing discussion.

\section{Acknowledgments:}

Availability of data and material: My manuscript and associated personal data will be shared with Research Square for the delivery of the author dashboard.

Compliance with ethical standards: The manuscript has not been published elsewhere and has not been submitted simultaneously for publication elsewhere.

Conflict of interest: The authors declare that they have no conflict of interest.

Declaration of Competing Interest: The authors declare that they have no known competing financial interests or personal relationships that could have appeared to influence the work reported in this paper.

Funding statement: There are currently no Funding Sources on the list

Consent to participate: The authors consent to participate.

Consent for Publication: The author's consent for publication.

\section{References}

[1] Shaaban, K. S., Abo-Naf, S. M., \& Hassouna, M. E. M. Physical and Structural Properties of Lithium Borate Glasses Containing $\mathrm{MoO}_{3}$. Silicon 11, 2421-2428, (2019). DOI:10.1007/s12633-016-9519-4 
[2] El-Rehim, A.F.A., Shaaban, K.S. (2021), Influence of $\mathrm{La}_{2} \mathrm{O}_{3}$ content on the structural, mechanical, and radiation-shielding properties of sodium fluoro lead barium borate glasses. J Mater Sci: Mater Electron. https://doi.org/10.1007/s10854-020-05204-7

[3] Shaaban, K. S., Abo-naf S. M., Abd Elnaeim, A. M., \& Hassouna, M. E. M. Studying effect of $\mathrm{MoO}_{3}$ on elastic and crystallization behavior of lithium diborate glasses. Applied Physics A, 123(6) 457, (2017). DOI:10.1007/s00339-017-1052-9

[4] Rao, L. S., Reddy, M. S., Rao, D. K., \& Veeraiah, N. Influence of redox behavior of copper ions on dielectric and spectroscopic properties of $\mathrm{Li}_{2} \mathrm{O}-\mathrm{MoO}_{3}-\mathrm{B}_{2} \mathrm{O}_{3}$ : $\mathrm{CuO}$ glass system. SolidState Sciences, 11(2), 578-587. (2009). DOI: 10.1016/j.solidstatesciences.2008.06.022

[5] Abd-Allah, W.M., Saudi, H.A., Shaaban, K.S. et al. Investigation of structural and radiation shielding properties of $40 \mathrm{~B}_{2} \mathrm{O}_{3}-30 \mathrm{PbO}-(30-x)$ BaO- $x \mathrm{ZnO}$ glass system. Appl. Phys. A 125, 275 (2019). https://doi.org/10.1007/s00339-019-2574-0

[6] Saudi, H.A., Abd-Allah, W.M. \& Shaaban, K.S. Investigation of gamma and neutron shielding parameters for borosilicate glasses doped europium oxide for the immobilization of radioactive waste. J Mater Sci: Mater Electron 31, 6963-6976 (2020). https://doi.org/10.1007/s10854-020-03261-6

[7] Somaily, H.H., Shaaban, K.S., Makhlouf, S.A. et al. Comparative Studies on Polarizability, Optical Basicity and Optical Properties of Lead Borosilicate Modified with Titania. J Inorg Organomet Polym (2020). https://doi.org/10.1007/s10904-020-01650-2

[8] Wahab, E. A. A., \& Shaaban, K. S. Effects of $\mathrm{SnO}_{2}$ on spectroscopic properties of borosilicate glasses before and after plasma treatment and its mechanical properties. Materials Research Express, 5(2), 025207, (2018). https://doi.org/10.1088/2053-1591/aaaee8

[9] Koubisy, M.S.I., Shaaban, K.S., Wahab, E.A.A. et al. (2021), Synthesis, structure, mechanical and radiation shielding features of $50 \mathrm{SiO}_{2}-(48+\mathrm{X}) \quad \mathrm{Na}_{2} \mathrm{~B}_{4} \mathrm{O}_{7}-(2-\mathrm{X})$ $\mathrm{MnO}_{2}$ glasses. Eur. Phys. J. Plus 136, 156, https://doi.org/10.1140/epjp/s13360-021-01125-4 
[10] E.A. Abdel Wahab, M.S.I. Koubisy, M.I. Sayyed, K.A. Mahmoud, A.F. Zatsepin, Sayed

A. Makhlouf, Shaaban, Kh.S. (2021), Novel borosilicate glass system: $\mathrm{Na}_{2} \mathrm{~B}_{4} \mathrm{O}_{7}-\mathrm{SiO}_{2}-\mathrm{MnO}_{2}$

Synthesis, average electronics polarizability, optical basicity, and gamma-ray shielding features, Journal of Non-Crystalline Solids, 553,120509, doi.org/10.1016/j.jnoncrysol.2020.120509

[11] El-Rehim, A.F.A., Zahran, H.Y., Yahia, I.S. et al. (2020). Physical, Radiation Shielding and Crystallization Properties of $\mathrm{Na}_{2} \mathrm{O}-\mathrm{Bi}_{2} \mathrm{O}_{3}-\mathrm{MoO}_{3}-\mathrm{B}_{2} \mathrm{O}_{3}-\mathrm{SiO}_{2} \mathrm{Fe}_{2} \mathrm{O}_{3}$ Glasses. Silicon, doi.org/10.1007/s12633-020-00827-1

[12] Shaaban, K.S., Yousef, E.S., Abdel Wahab, E.A. et al. (2020). Investigation of Crystallization and Mechanical Characteristics of Glass and Glass-Ceramic with the Compositions $x \mathrm{Fe}_{2} \mathrm{O}_{3}-35 \mathrm{SiO}_{2}-35 \mathrm{~B}_{2} \mathrm{O}_{3}-10 \mathrm{Al}_{2} \mathrm{O}_{3}-(20-x) \quad \mathrm{Na}_{2} \mathrm{O}$. J. of Materi Eng and Perform. https://doi.org/10.1007/s11665-020-04969-6

[13] El-Rehim, A.F.A., Zahran, H.Y., Yahia, I.S. et al. Structural, Elastic Moduli, and Radiation Shielding of $\mathrm{SiO}_{2}-\mathrm{TiO}_{2}-\mathrm{La}_{2} \mathrm{O}_{3}-\mathrm{Na}_{2} \mathrm{O}$ Glasses Containing $\mathrm{Y}_{2} \mathrm{O}_{3}$. J. of Materi Eng and Perform (2021). https://doi.org/10.1007/s11665-021-05513-w

[14] S. Singh, G. Kalia and K. Singh, Effect of Intermediate Oxide $\left(\mathrm{Y}_{2} \mathrm{O}_{3}\right)$ on Thermal, Structural and Optical Properties of Lithium Borosilicate Glasses, Mol. Struct., 1086, 239-245. (2015), https://doi.org/10.1016/j.molstruc.2015.01.031

[15] Shaaban, K.S., Wahab, E.A.A., Shaaban, E.R. et al. (2020). Electronic Polarizability, Optical Basicity, Thermal, Mechanical and Optical Investigations of $\left(65 \mathrm{~B}_{2} \mathrm{O}_{3}-30 \mathrm{Li}_{2} \mathrm{O}-\right.$ $5 \mathrm{Al}_{2} \mathrm{O}_{3}$ ) Glasses Doped with Titanate. Journal of Elec Materi 49, 2040-2049.

\section{https://doi.org/10.1007/s11664-019-07889-x}

[16] Shaaban, K.S., Koubisy, M.S.I., Zahran, H.Y. et al. (2020). Spectroscopic Properties, Electronic Polarizability, and Optical Basicity of Titanium-Cadmium Tellurite Glasses Doped with Different Amounts of Lanthanum. J Inorg Organomet Polym. https://doi.org/10.1007/s10904-020-01640-4 
[17] Shaaban, K.S., Wahab, E.A.A., Shaaban, E.R. et al. (2020). Electronic polarizability, optical basicity and mechanical properties of aluminum lead phosphate glasses. Opt Quant Electron 52, 125 https://doi.org/10.1007/s11082-020-2191-3

[18] Shaaban, K.S., Yousef, E.S., Mahmoud, S.A. et al. (2020). Mechanical, Structural and Crystallization Properties in Titanate Doped Phosphate Glasses. J Inorg Organomet. Polym https://doi.org/10.1007/s10904-020-01574-X

[19] Şakar, E., Özpolat, Öü.F1., Alım, Bü., Sayyed, M.I., Kurudirek, M., (2020). PhyX / PSD: Development of a user friendly online software for calculation of parameters relevant to radiation shielding and dosimetry, Radiation Physics and Chemistry 166, 108496, https://doi.org/10.1016/j.radphyschem.2019.108496

[20] Makishima, A. and J.D. Mackenzie, (1973), Direct calculation of Young's modulus of glass. Journal of Non-Crystalline Solids, 12(1), 35-45, https://doi.org/10.1016/0022$\underline{3093(73) 90053-7}$

[21] Makishima, A. and J.D. Mackenzie, (1975), Calculation of bulk modulus, shear modulus, and Poisson's ratio of glass. Journal of Non-crystalline solids, 17(2) 147-157, https://doi.org/10.1016/0022-3093(75)90047-2

[22] Kodama, M. Ultrasonic velocity in sodium borate glasses. J Mater Sci 26, 4048-4053 (1991). https://doi.org/10.1007/BF02402945

[23] Ulrike Veit, Christian Rüssel, Elastic properties of quaternary glasses in the $\mathrm{MgO}-\mathrm{CaO}-$ $\mathrm{Al}_{2} \mathrm{O}_{3}-\mathrm{SiO}_{2}$ system: modeling versus measurement, J. Mater. Sci. 52 8159-8175, (2017). DOI: $\underline{10.1007 / s 10853-017-1023-8}$

[24] El-Rehim, A.A., Zahran, H., Yahia, I. et al. (2020). Radiation, Crystallization, and Physical Properties of Cadmium Borate Glasses. Silicon https://doi.org/10.1007/s12633-02000798-3 
[28] Shaaban, K.S., Zahran, H.Y., Yahia, I.S. et al. (2020), Mechanical and radiation-shielding properties of $\mathrm{B}_{2} \mathrm{O}_{3}-\mathrm{P}_{2} \mathrm{O}_{5}-\mathrm{Li}_{2} \mathrm{O}-\mathrm{MoO}_{3}$ glasses. Appl. Phys. A 126, (10), 804. https://doi.org/10.1007/s00339-020-03982-9

[29] El-Sharkawy, R. M., Shaaban, K. S., Elsaman, R., Allam, E. A., El-Taher, A., \& Mahmoud, M. E. (2020). Investigation of mechanical and radiation shielding characteristics of novel glass systems with the composition $\mathrm{xNiO}-20 \mathrm{ZnO}-60 \mathrm{~B}_{2} \mathrm{O}_{3}-(20-\mathrm{x}) \mathrm{CdO}$ based on nano metal oxides. Journal of Non-Crystalline Solids, 528,119754 doi: 10.1016/j.jnoncrysol.2019.119754

[30] El-Rehim, A.F.A., Zahran, H.Y., Yahia, I.S. et al. (2020). Physical, Radiation Shielding and Crystallization Properties of $\mathrm{Na}_{2} \mathrm{O}_{-}-\mathrm{Bi}_{2} \mathrm{O}_{3-} \quad \mathrm{MoO}_{3}-\mathrm{B}_{2} \mathrm{O}_{3^{-}} \quad \mathrm{SiO}_{2^{-}}$ $\mathrm{Fe}_{2} \mathrm{O}_{3}$ Glasses. Silicon https://doi.org/10.1007/s12633-020-00827-1 
Figures

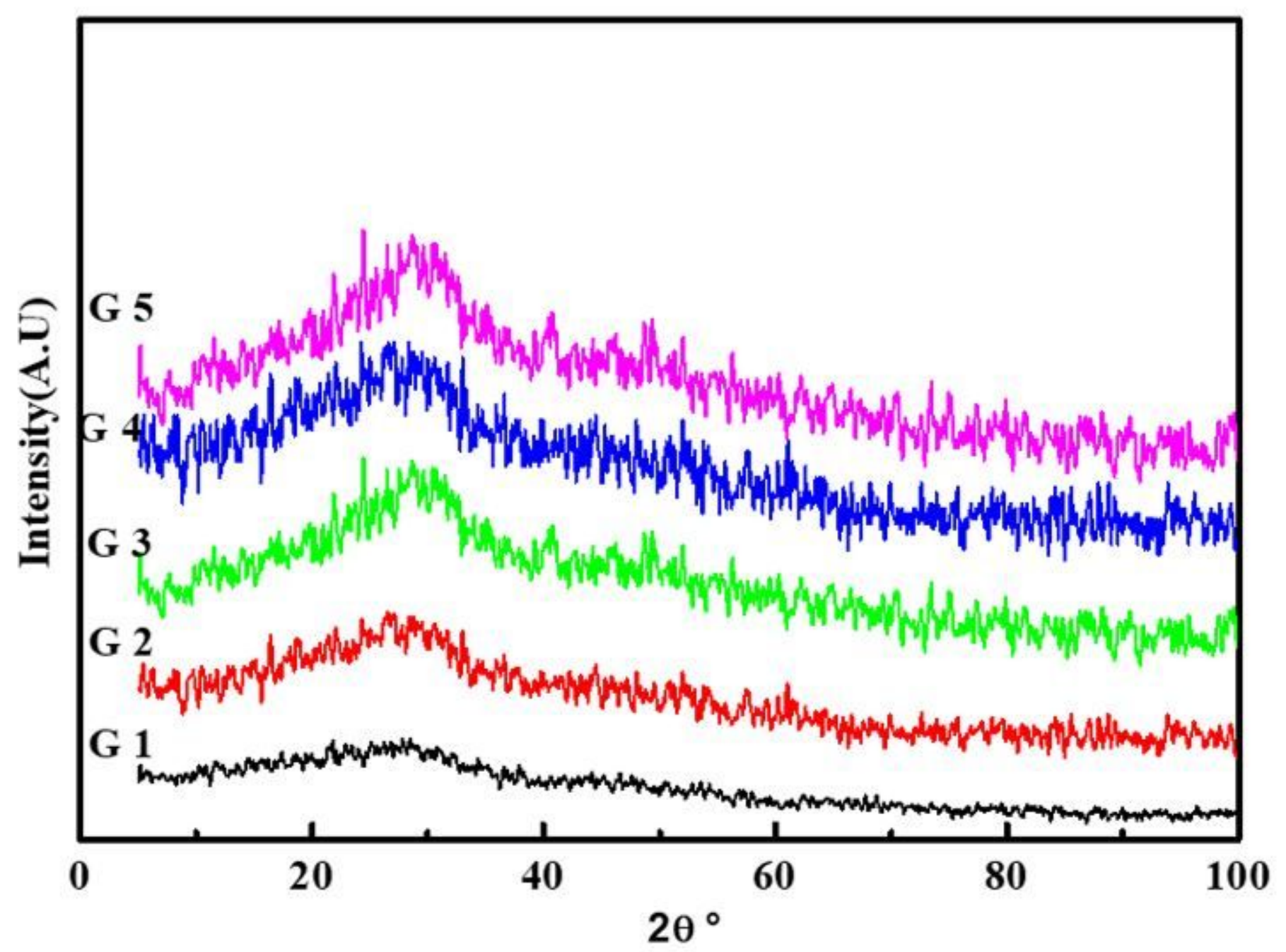

Figure 1

XRD of the studied glasses. 


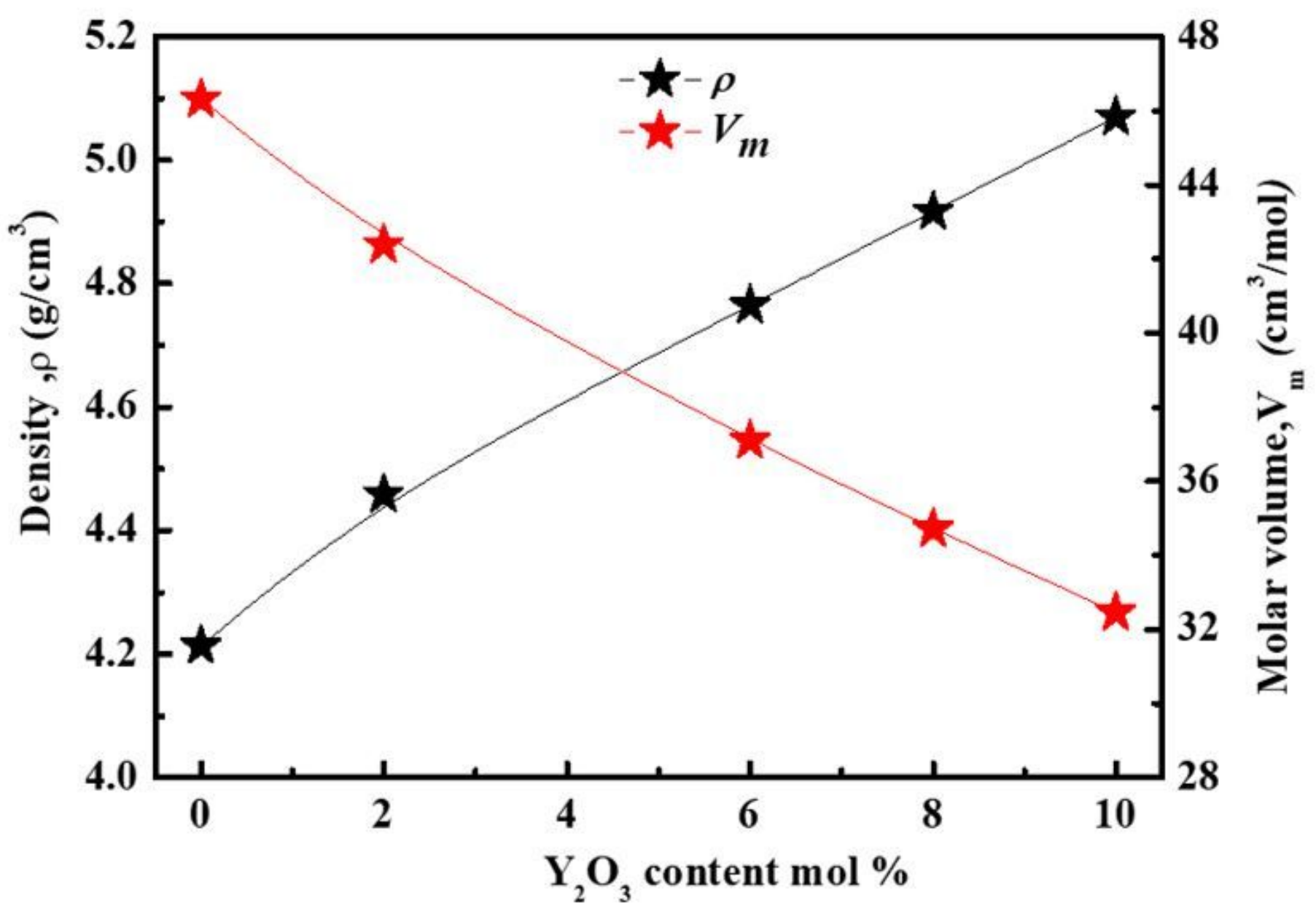

Figure 2

Density and molar volume of the prepared samples versus Y2O3 concentration in mol \%. 


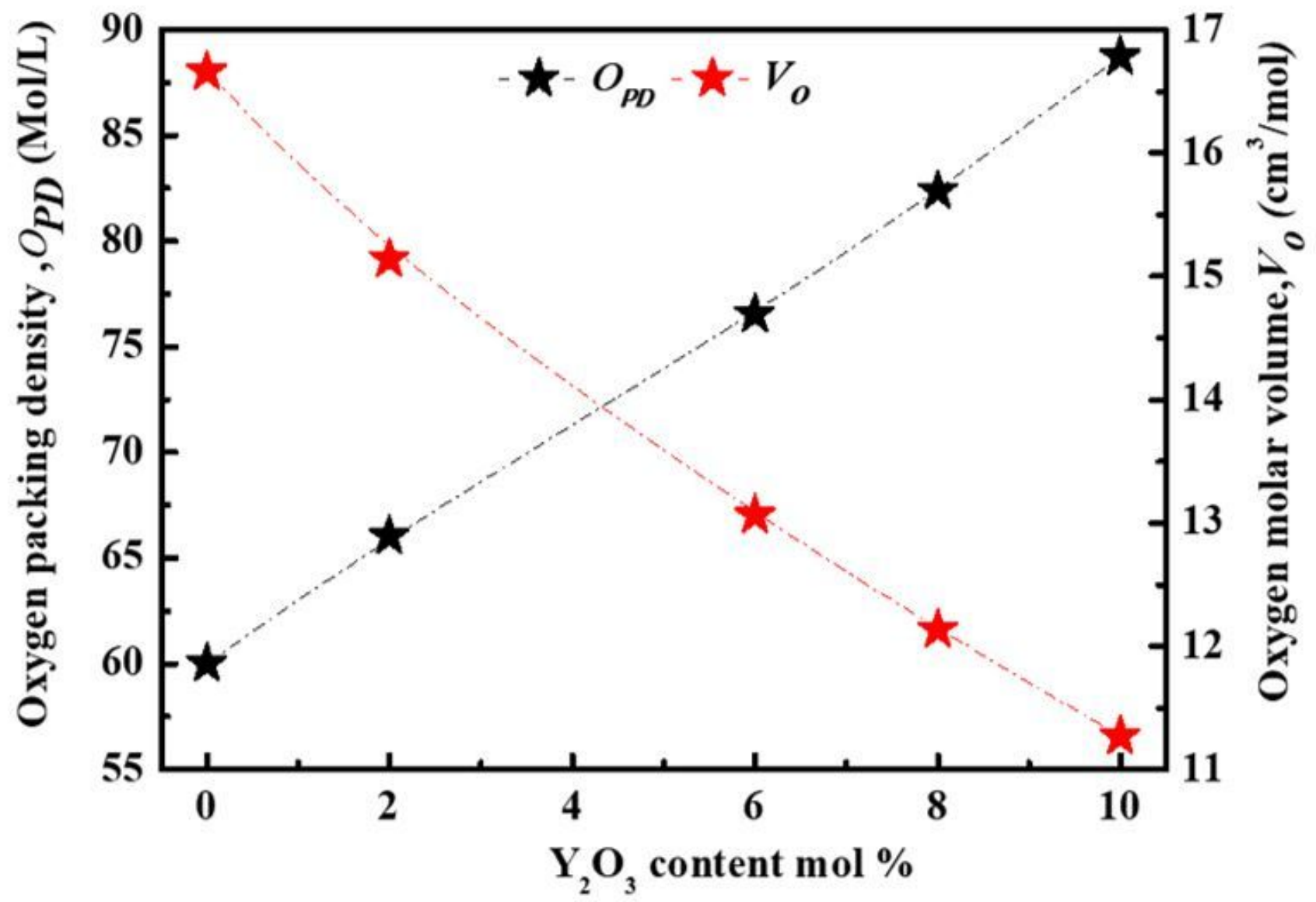

Figure 3

Oxygen packing density and oxygen molar volume of the investigated glasses versus content of Y2O3 $\mathrm{mol} . \%$. 


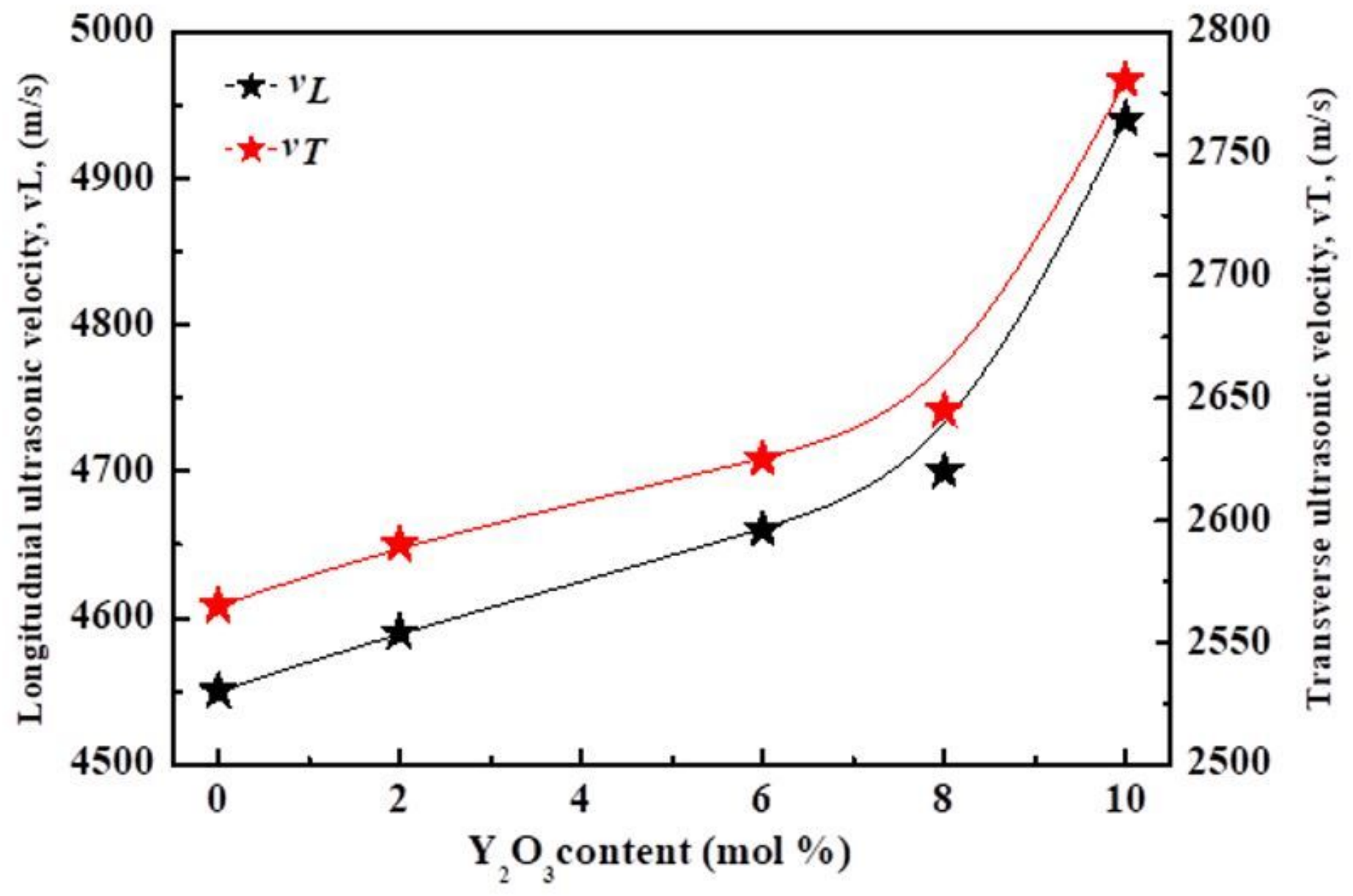

Figure 4

Dependence of the longitudinal and shear ultrasonic velocities $v L$ and $v T$ of the investigated glasses with Y203 concentration by mol. \%. 


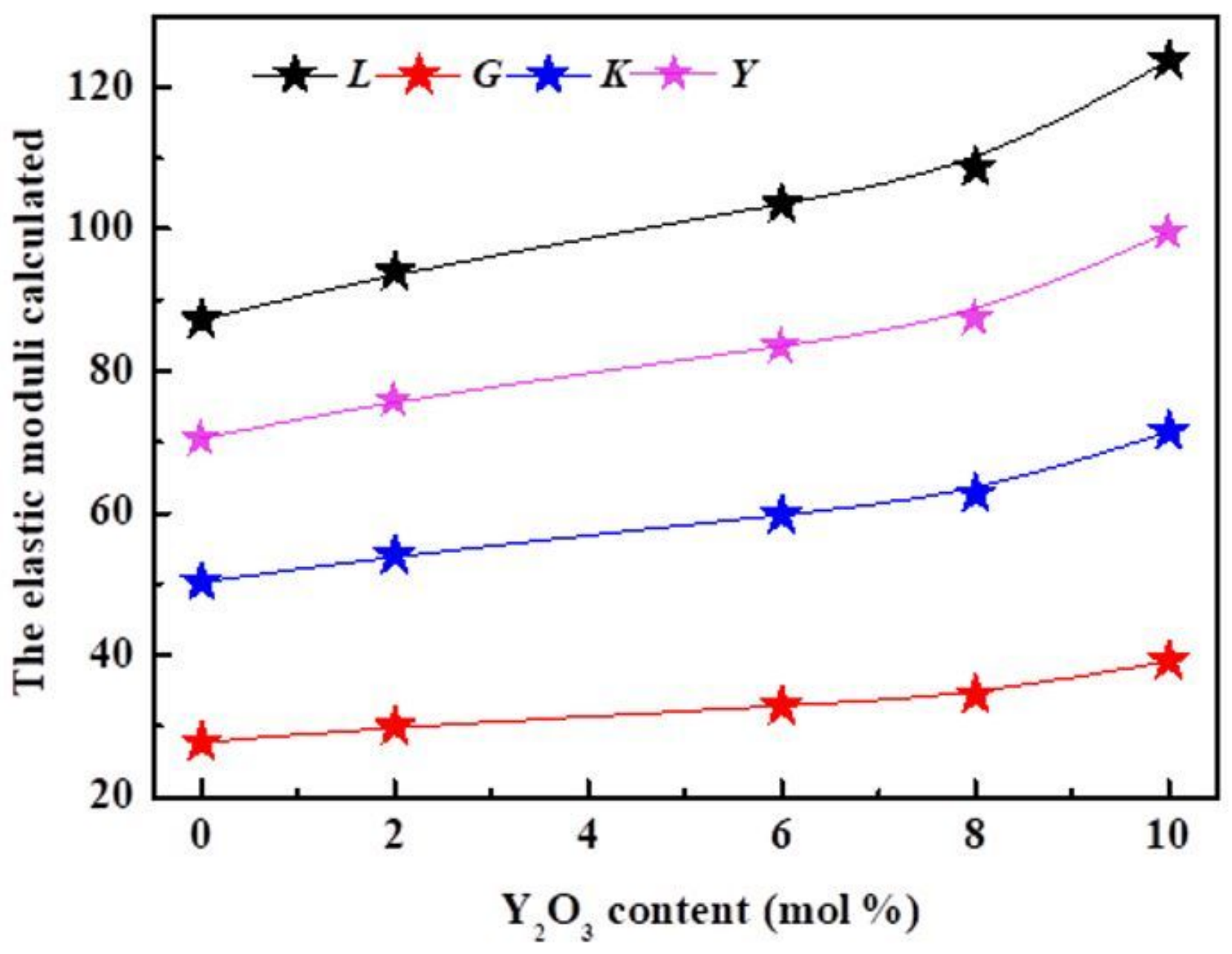

Figure 5

Elastic moduli calculated of the studied glasses with Y203 content by mol. \%. 


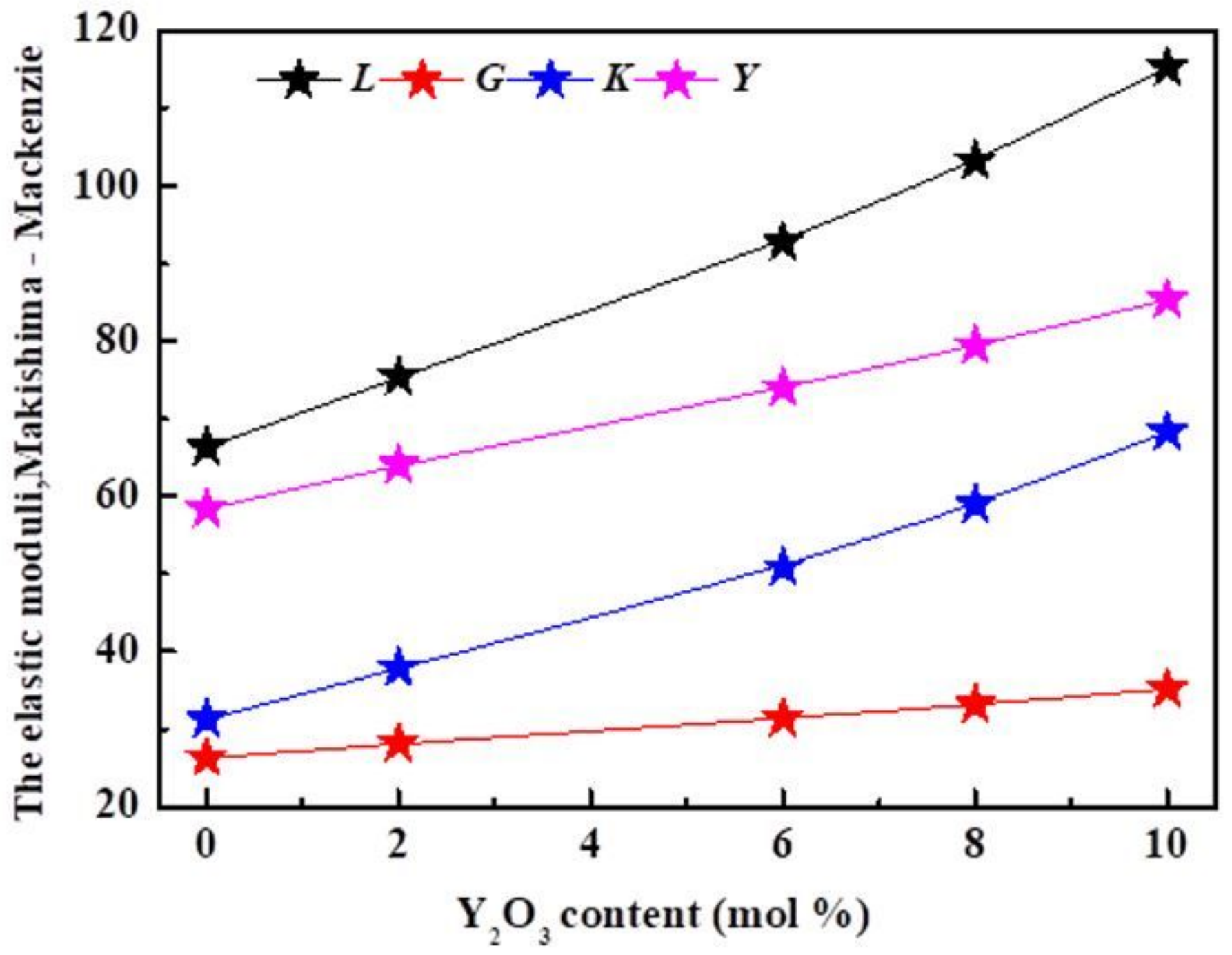

Figure 6

Elastic moduli theoretically of the studied glasses with Y2O3 content by mol. \%, according to Makishima - Mackenzie Model. 


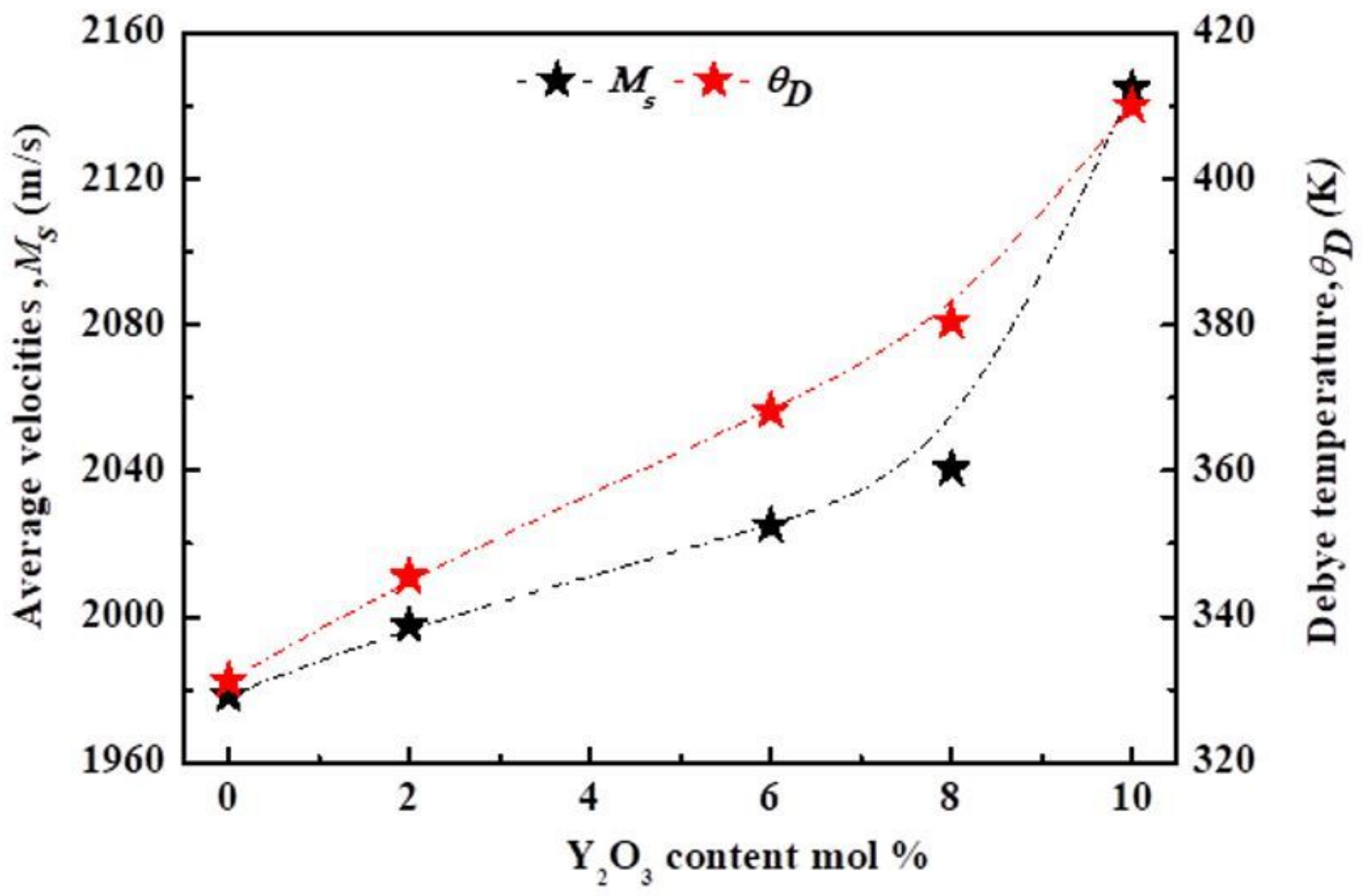

Figure 7

Debye temperature and average velocities of the studied glasses with Y2O3 concentration by mol. \%. 


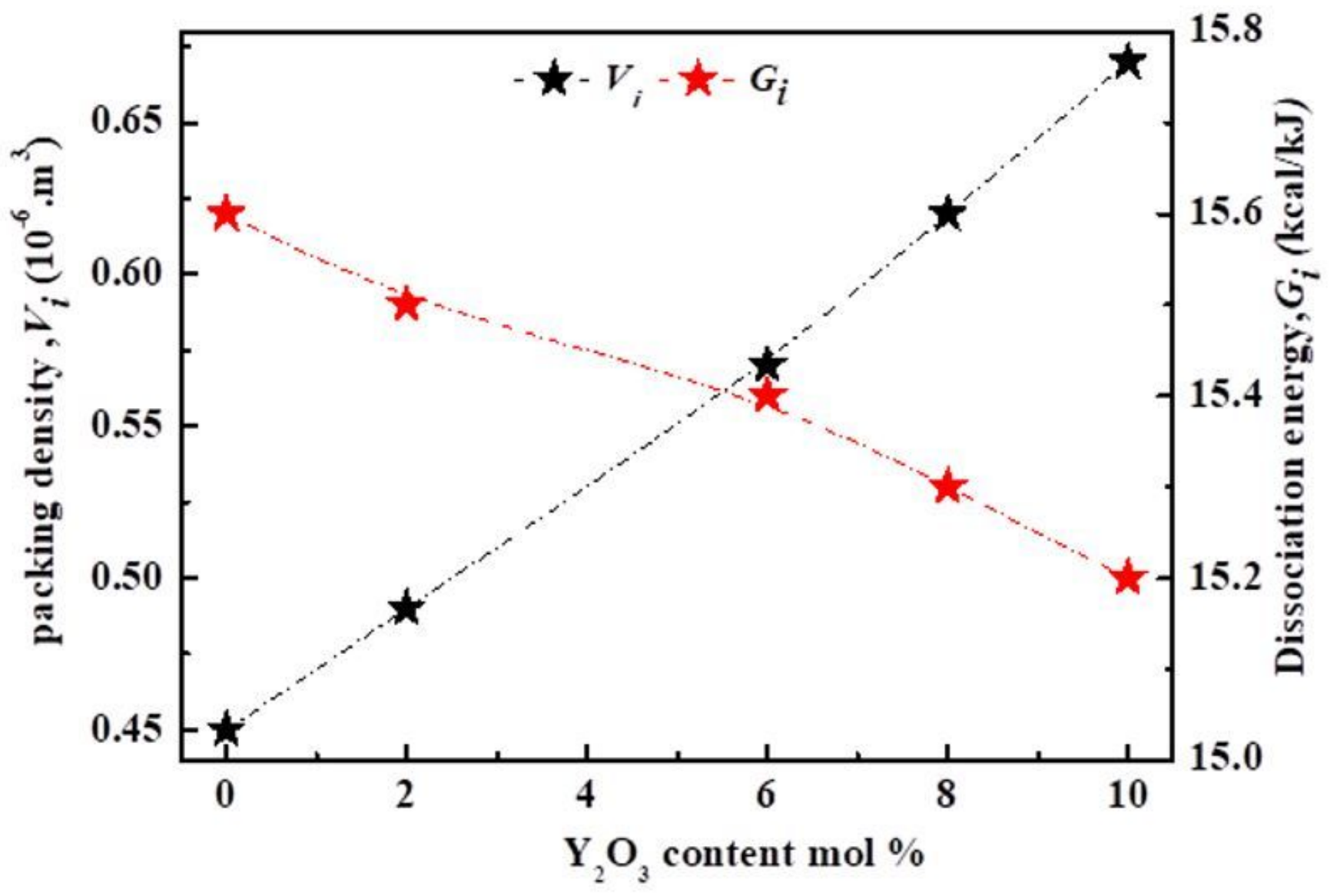

Figure 8

Values of packing density ( $\mathrm{Vi})$, dissociation energy (Gi), of glass system doped and undoped $\mathrm{Y} 2 \mathrm{O} 3$ oxide by mol. \%. 


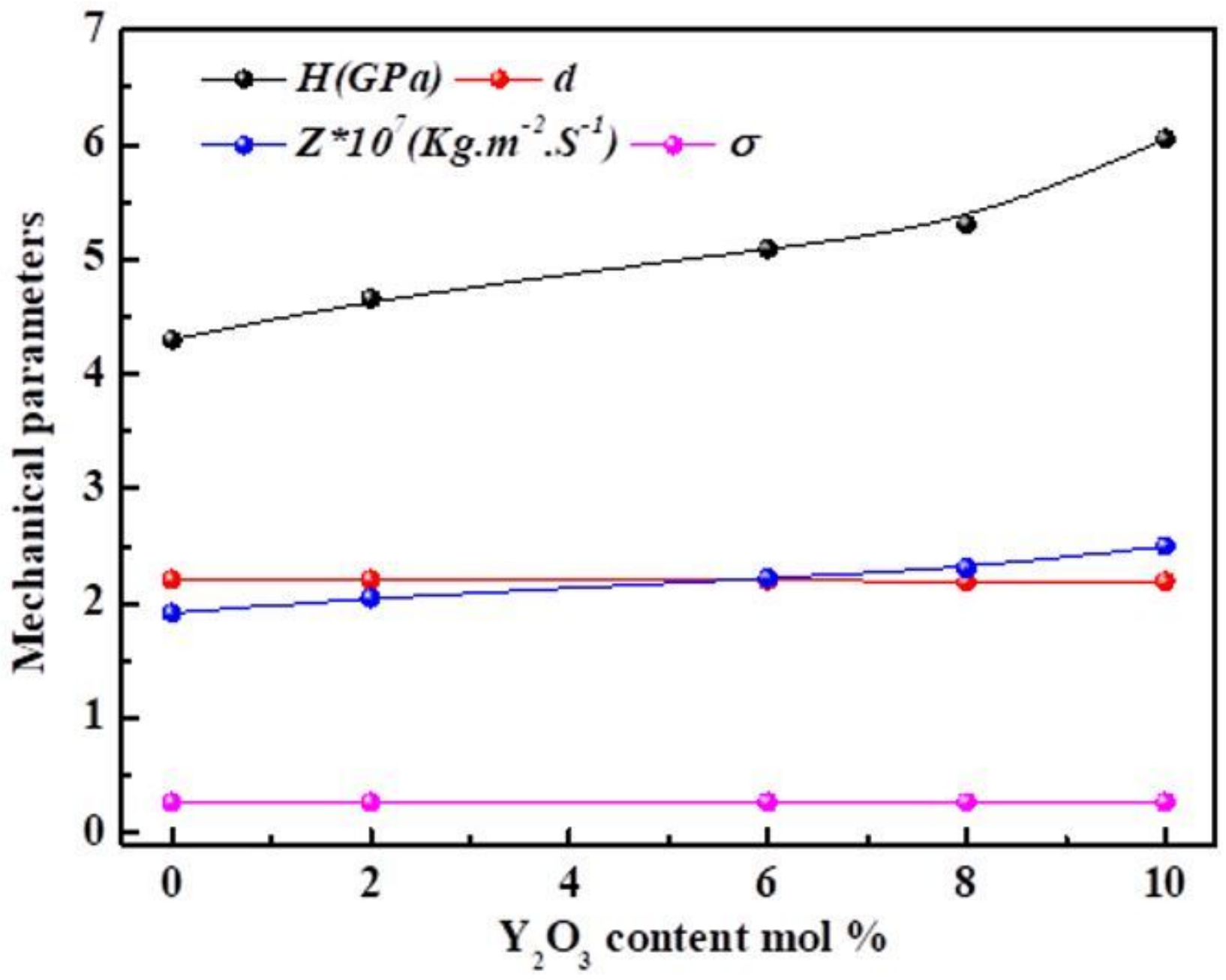

Figure 9

Acoustic impedance $(Z)$, dimensionality $(d)$, Poisson ratio $(\sigma)$ and micro-hardness $(H)$ of glass system doped and undoped Y2O3 oxide by mol. \%. 


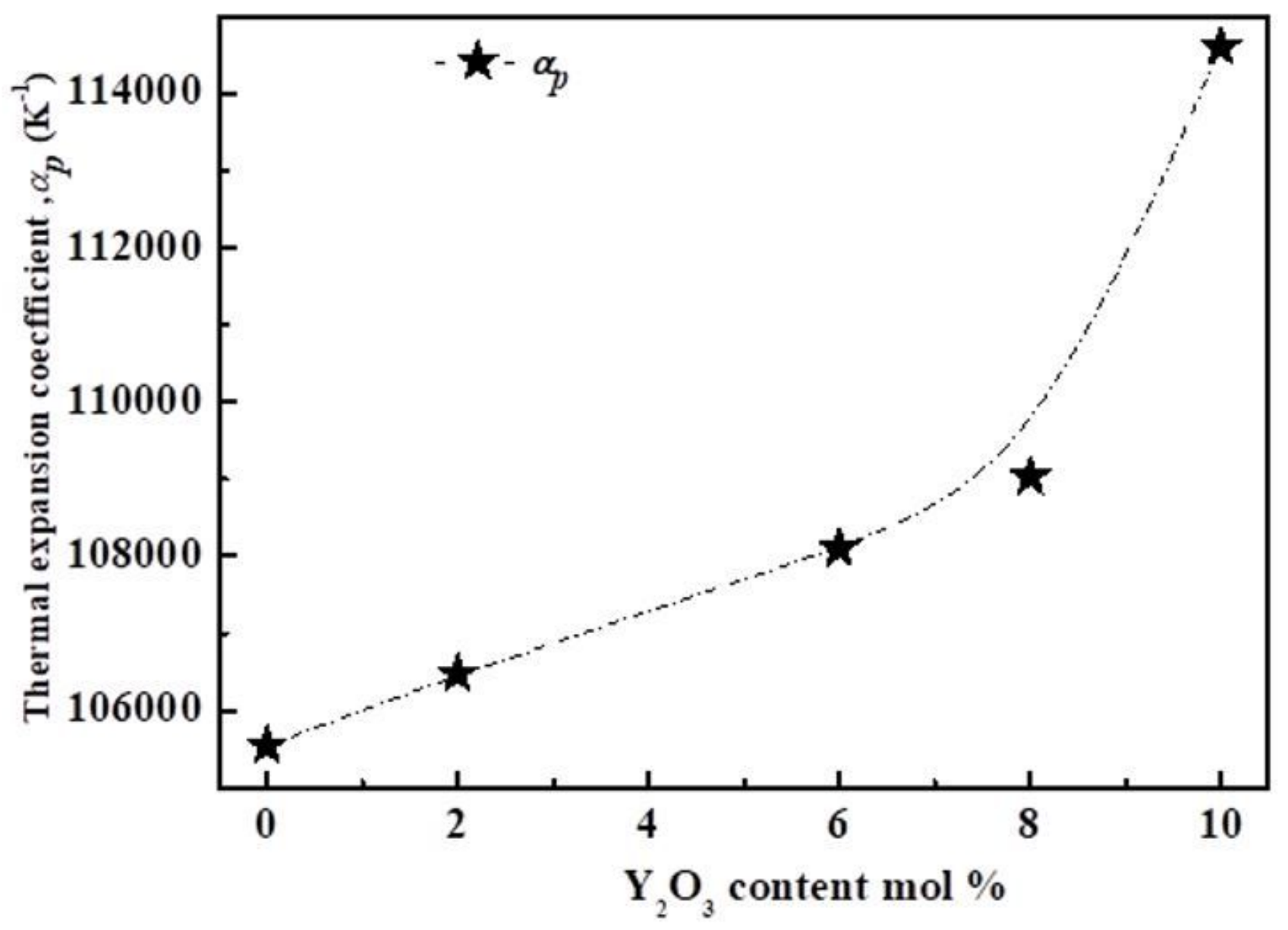

Figure 10

Thermal expansion coefficient $\mathrm{aP},(\mathrm{K}-1)$, of glass system doped and undoped $\mathrm{Y} 203$ oxide by $\mathrm{mol}$. \%. 


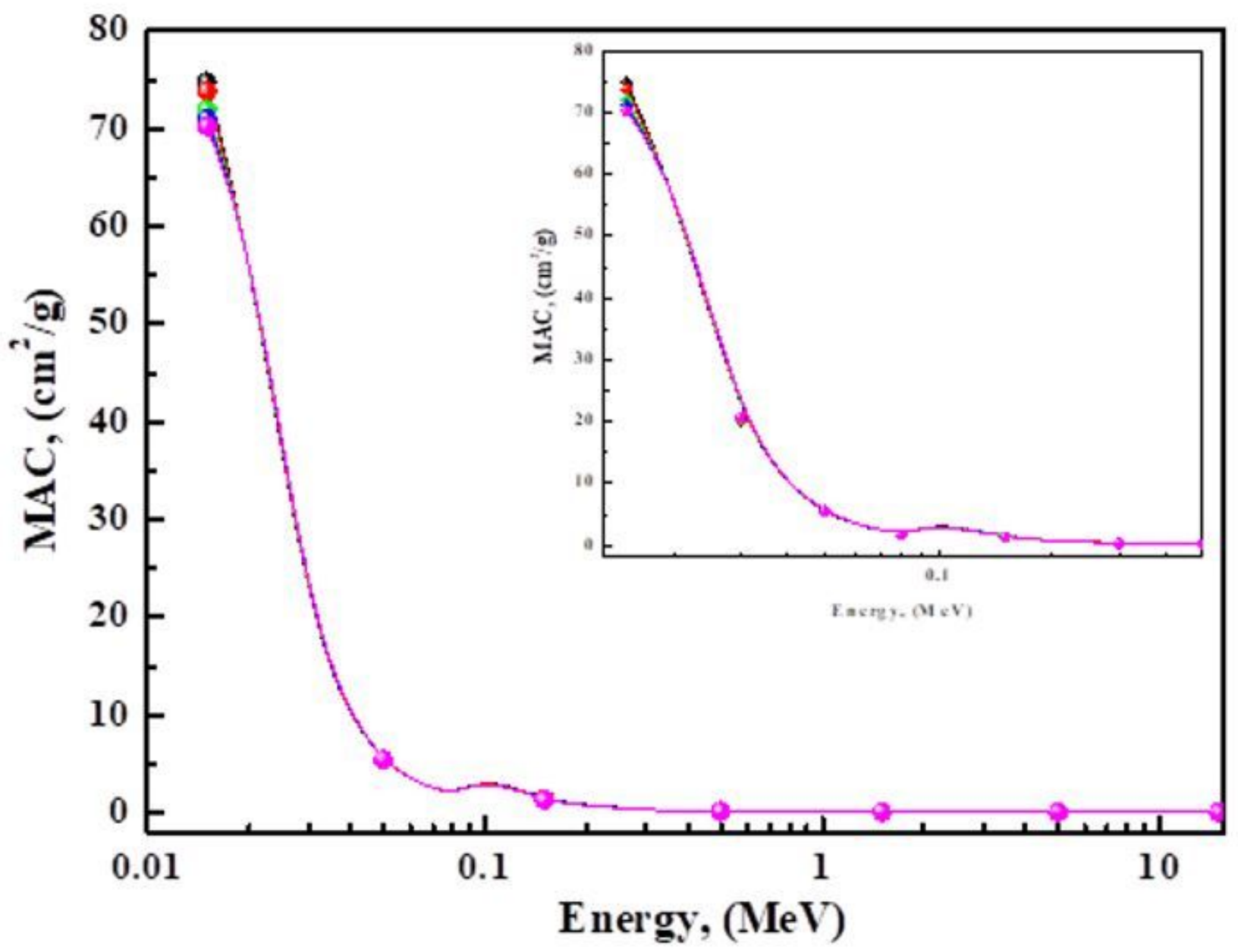

Figure 11

Mass attenuation coefficient prepared glasses a function of photon energy according to Phy-X/PSD. 


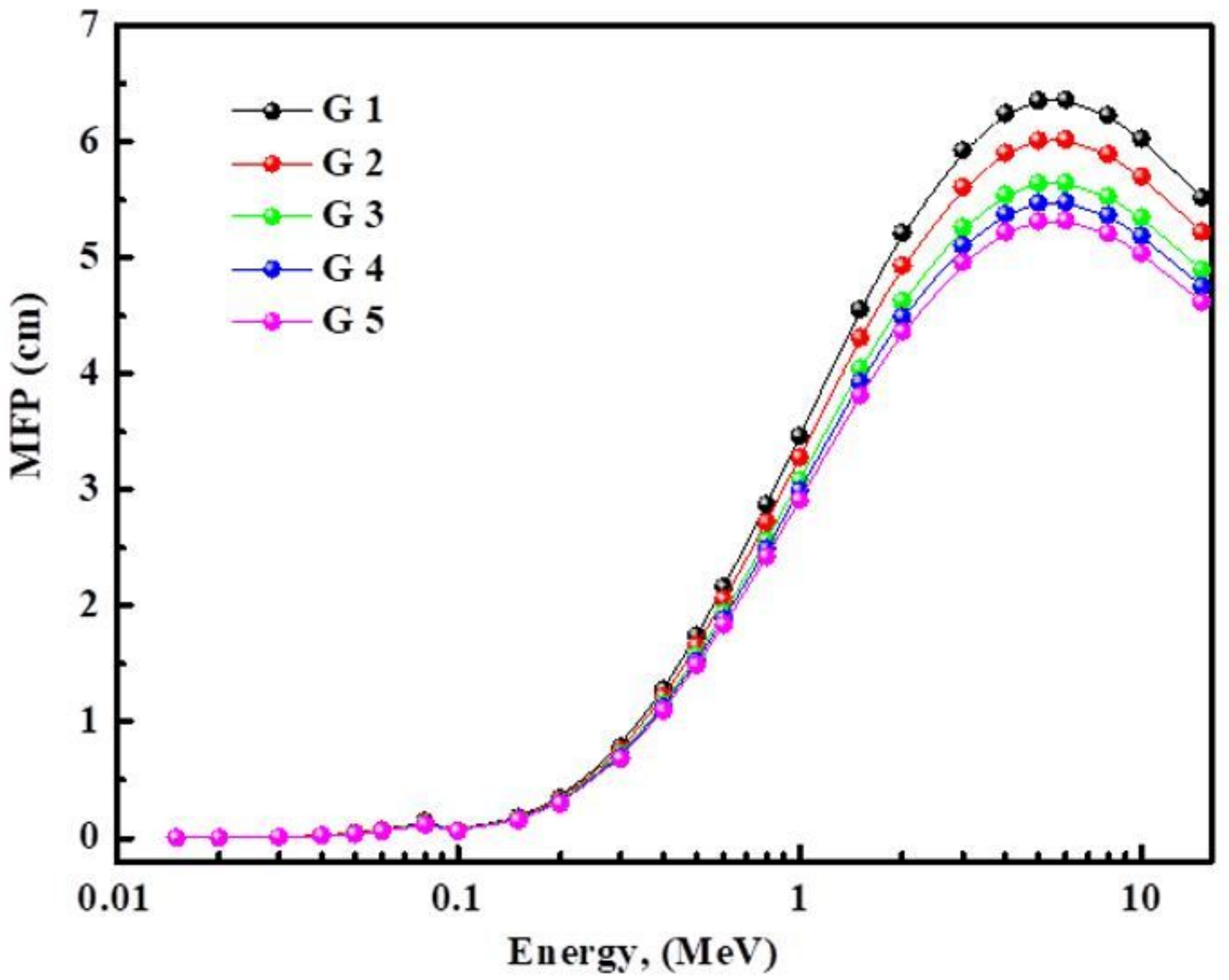

Figure 12

Mean free path of prepared glasses a function of photon energy according to Phy-X/PSD. 


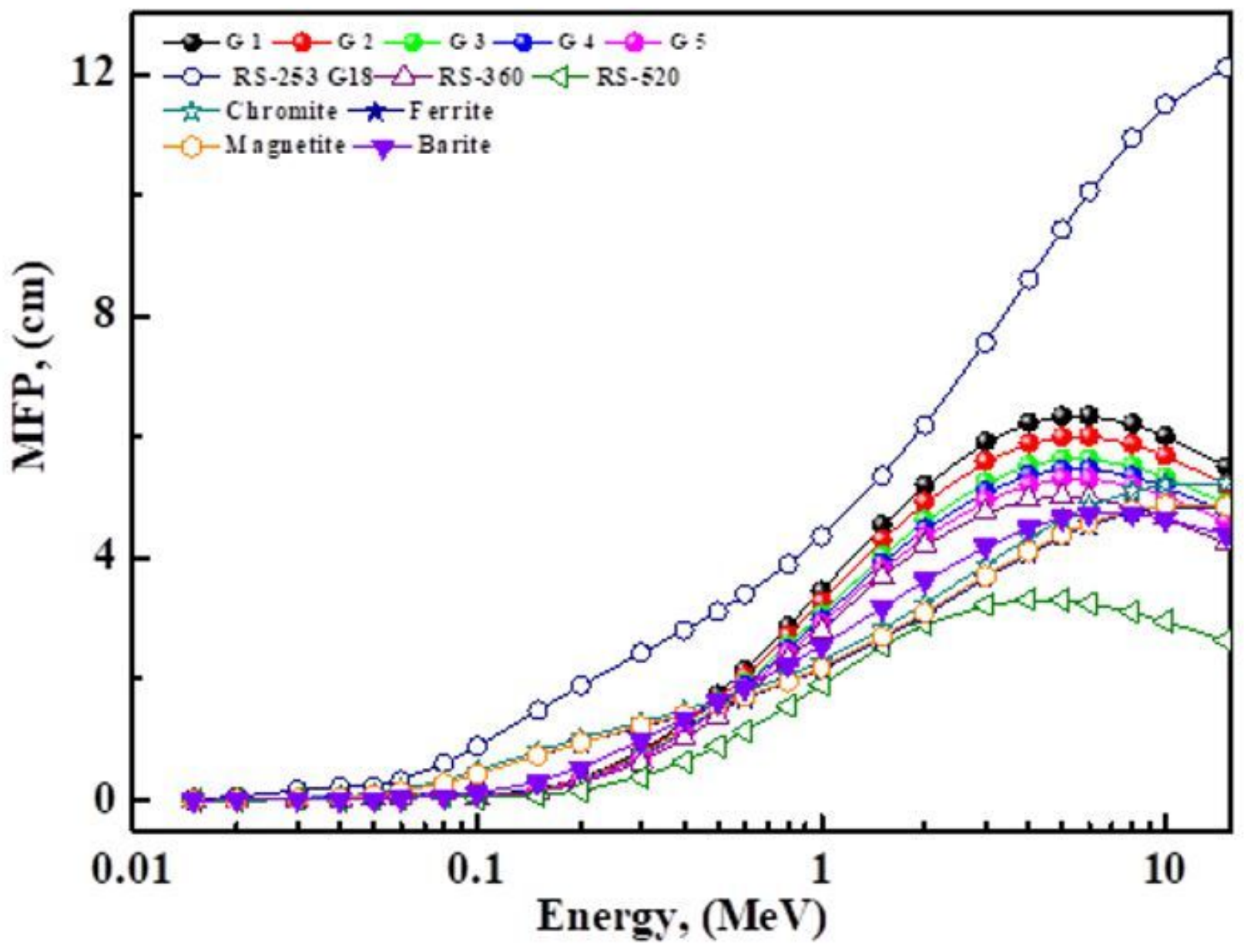

Figure 13

Comparison of MFP of prepared glasses with other materials. 


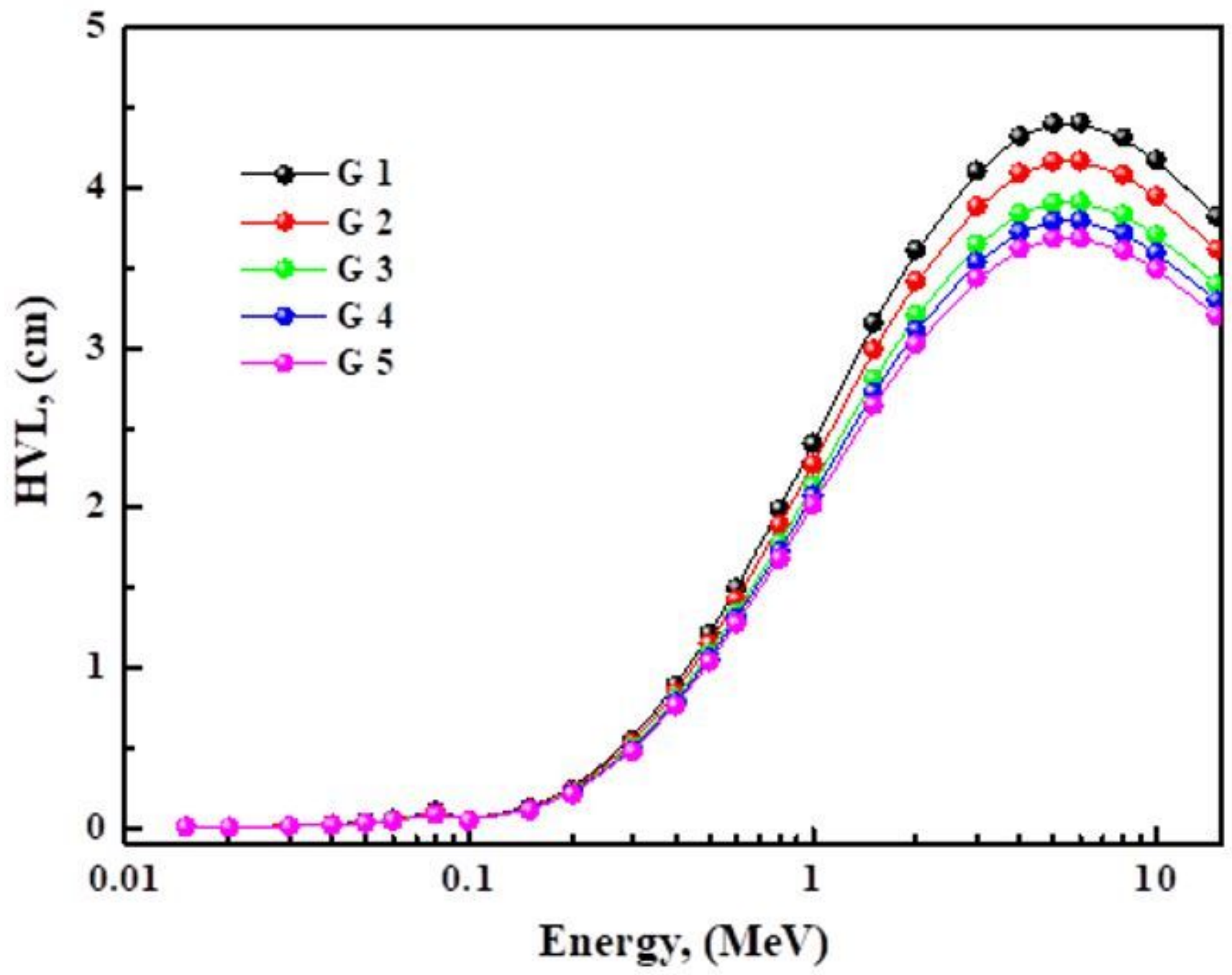

Figure 14

Have value layer of prepared glasses a function of photon energy according to Phy-X/PSD. 


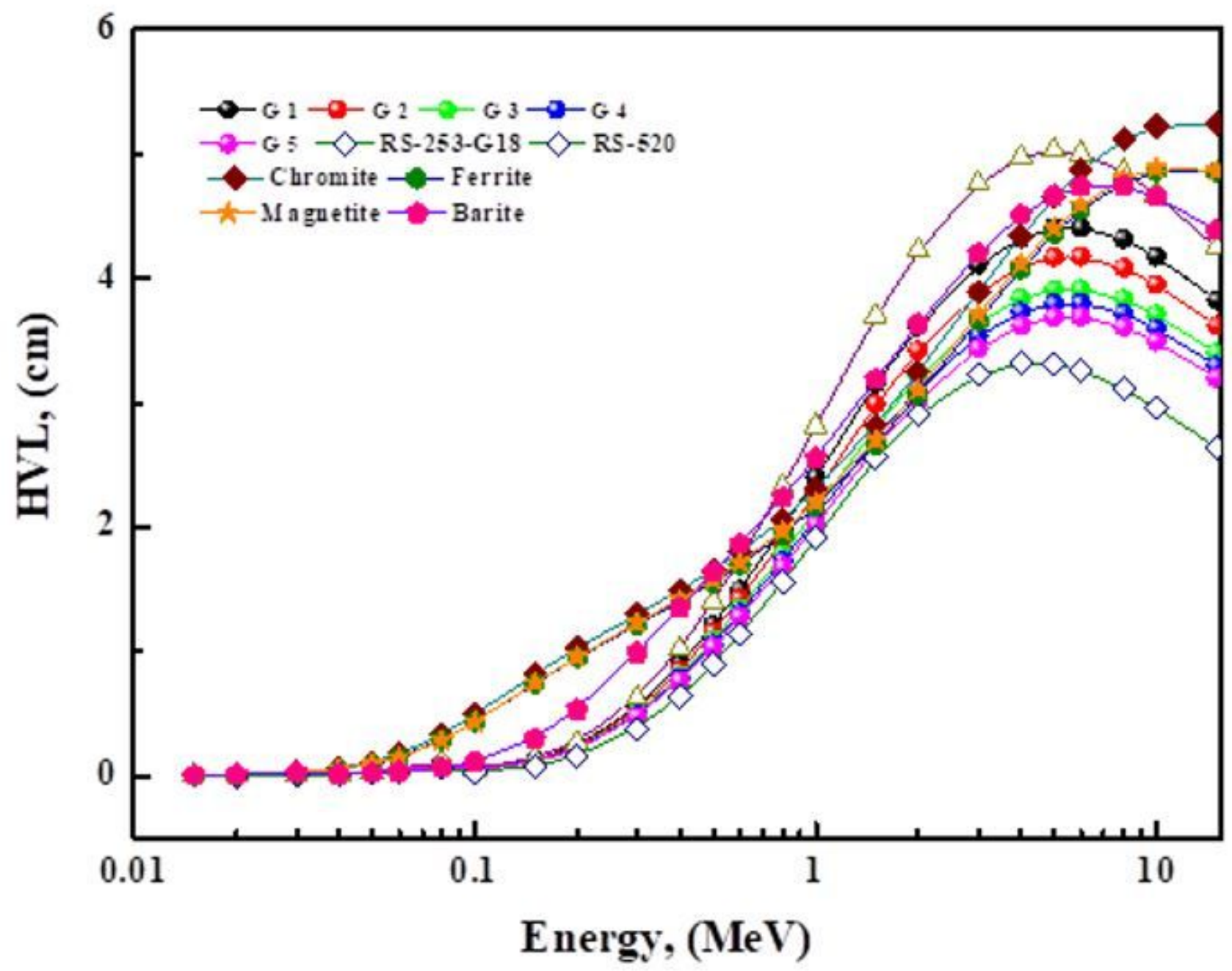

Figure 15

Comparison of HVL of prepared glasses with other materials. 


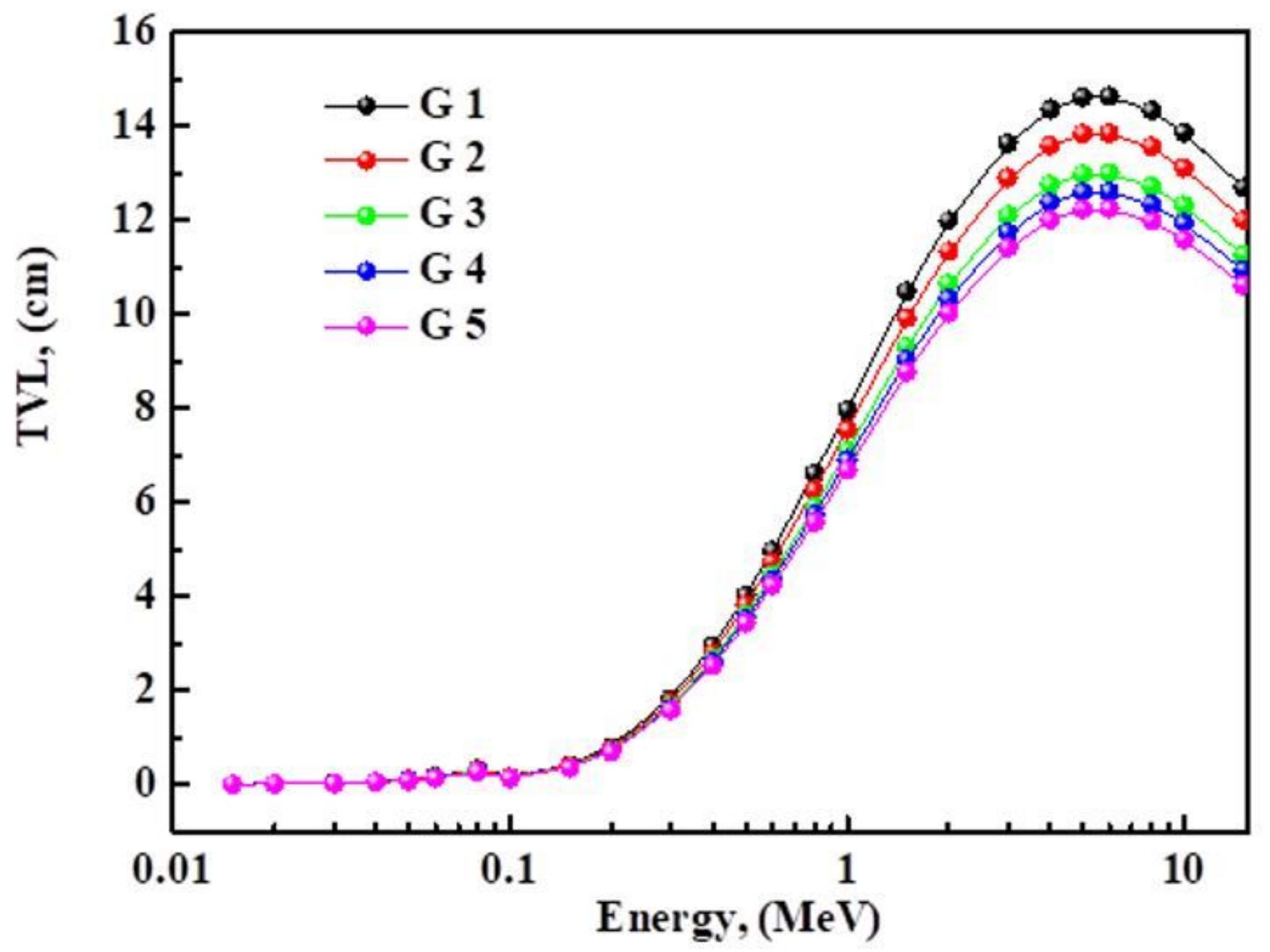

Figure 16

Tenth value layer of prepared glasses a function of photon energy according to Phy-X/PSD. 


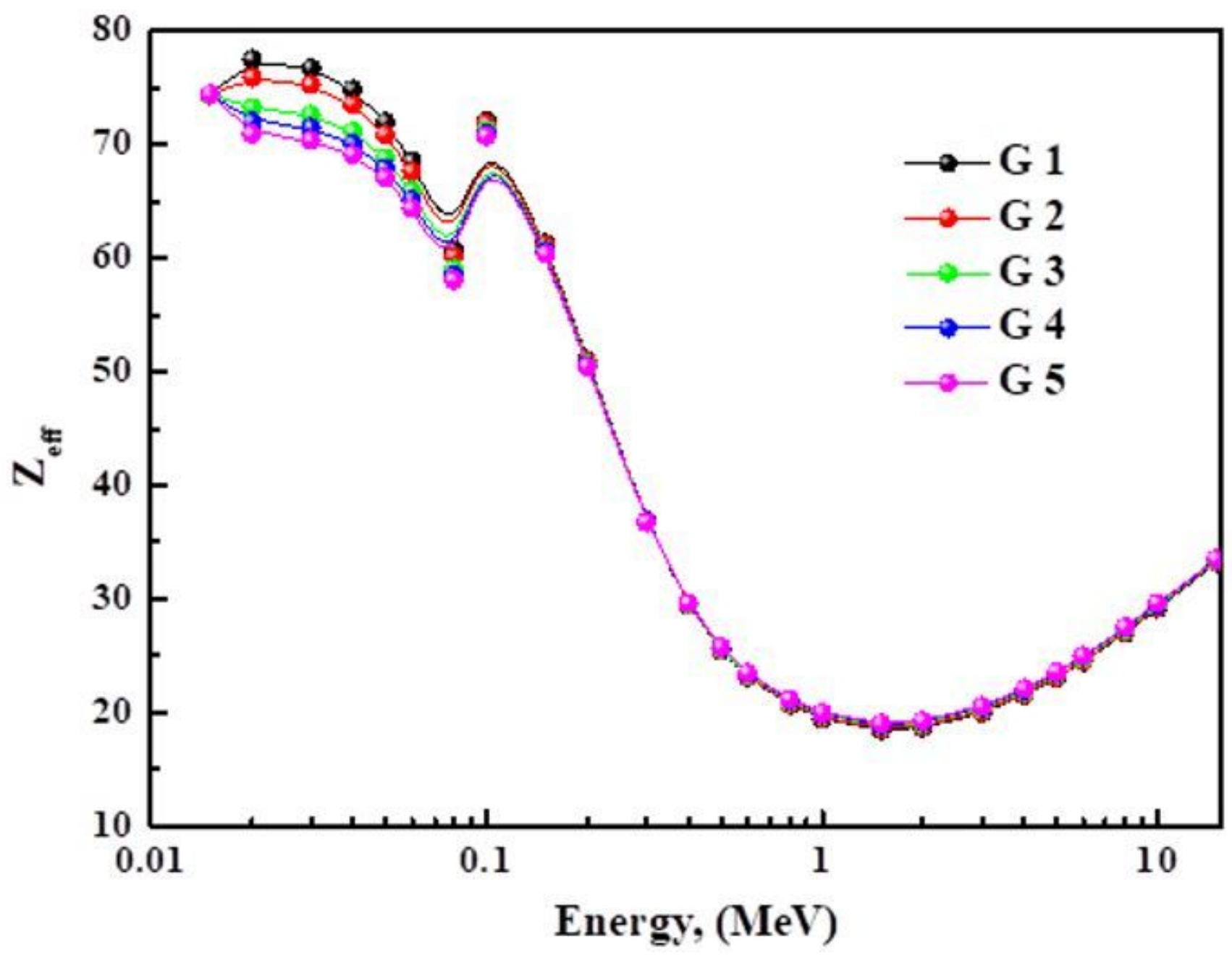

Figure 17

Zeff of prepared glasses a function of photon energy according to Phy-X/PSD. 


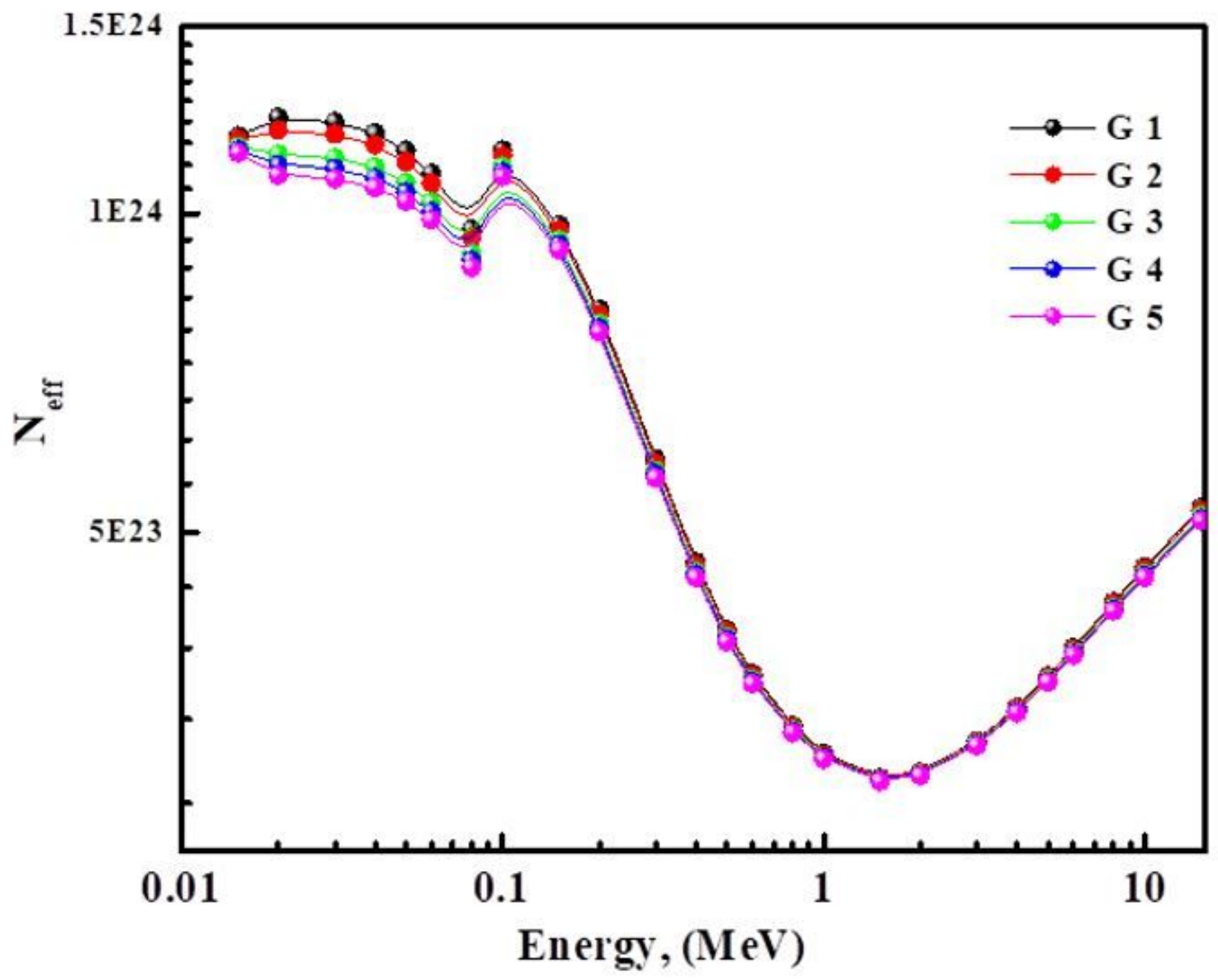

Figure 18

Neff of prepared glasses a function of photon energy according to Phy-X/PSD. 


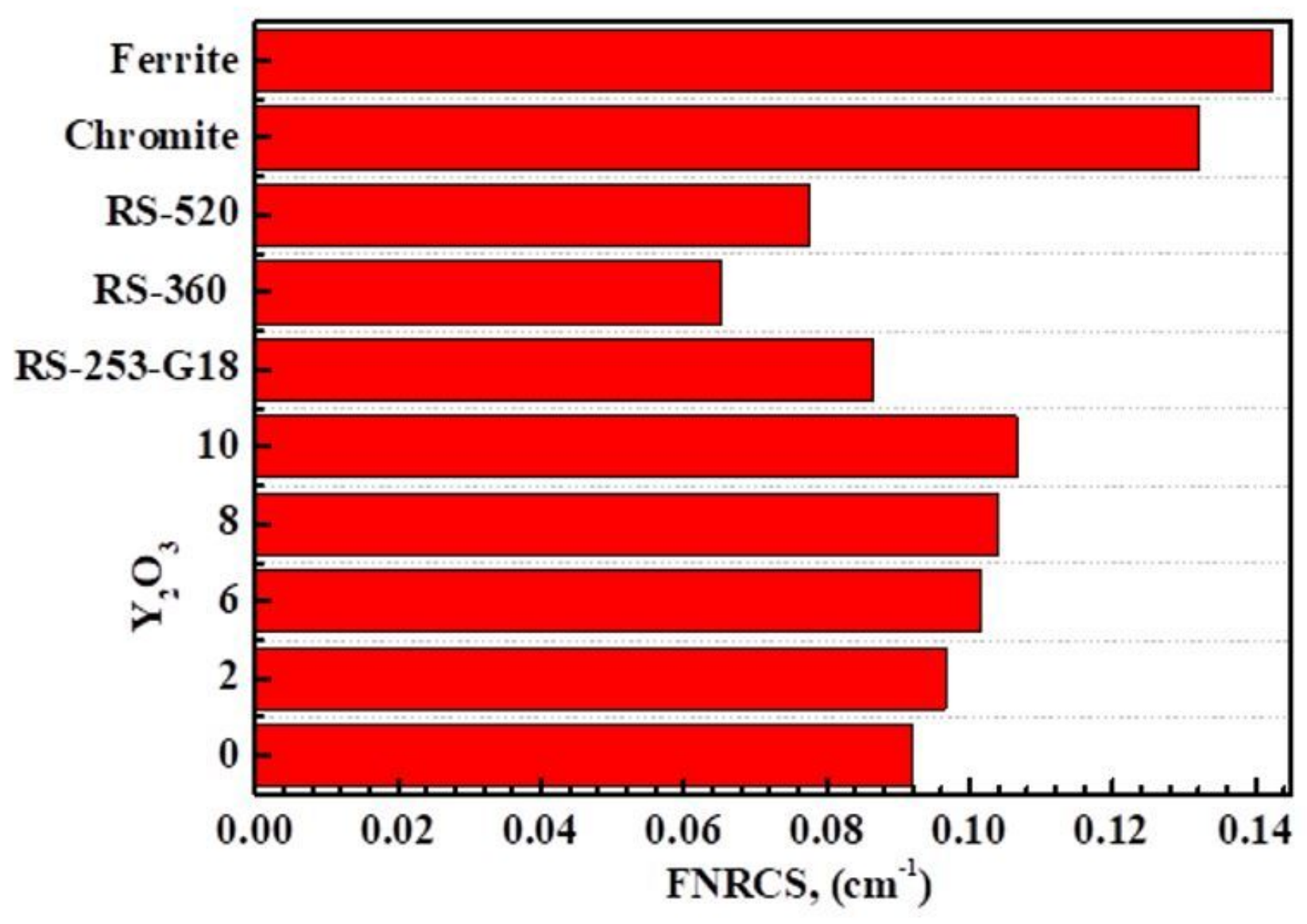

Figure 19

FNRCS of prepared glasses a function of photon energy according to Phy-X/PSD. 